Article

\title{
Research on Fuel Efficiency and Emissions of Converted Diesel Engine with Conventional Fuel Injection System for Operation on Natural Gas
}

\author{
Sergejus Lebedevas ${ }^{1}$, Saugirdas Pukalskas ${ }^{2}$, , Vygintas Daukšys $^{1}{ }^{10}$, Alfredas Rimkus ${ }^{2}$, \\ Mindaugas Melaika ${ }^{2}$ and Linas Jonika ${ }^{1, *}$ \\ 1 Department of Marine Engineering, Faculty of Marine Technologies and Natural Sciences, Klaipeda \\ University, Bijunu Str. 17, LT-91225 Klaipeda, Lithuania; sergejus.lebedevas@ku.lt (S.L.); \\ vygintasdauksys@gmail.com (V.D.) \\ 2 Department of Automobile Engineering, Transport Engineering Faculty, Vilnius Gediminas Technical \\ University, J. Basanavičiaus Str. 28, LT-03224 Vilnius, Lithuania; saugirdas.pukalskas@vgtu.lt (S.P.); \\ alfredas.rimkus@vgtu.lt (A.R.); mindaugas.melaika@gmail.com (M.M.) \\ * Correspondence: linas.jonika@apc.ku.lt
}

Received: 20 May 2019; Accepted: 19 June 2019; Published: 23 June 2019

\begin{abstract}
This paper presents a study on the energy efficiency and emissions of a converted high-revolution bore $79.5 \mathrm{~mm} /$ stroke $95 \mathrm{~mm}$ engine with a conventional fuel injection system for operation with dual fuel feed: diesel (D) and natural gas (NG). The part of NG energy increase in the dual fuel is related to a significant deterioration in energy efficiency $\left(\eta_{i}\right)$, particularly when engine operation is in low load modes and was determined to be below $40 \%$ of maximum continuous rating. The effectiveness of the $\mathrm{D}$ injection timing optimisation was established in high engine load modes within the range of a co-combustion ratio of $\mathrm{NG} \leq 0.4$ : with an increase in $\eta_{i}$, compared to D, the emissions of $\mathrm{NO}_{x}+\mathrm{HC}$ decreased by $15 \%$ to $25 \%$, while those of $\mathrm{CO}_{2}$ decreased by $8 \%$ to $16 \%$; the six-fold CO emission increase, up to $6 \mathrm{~g} / \mathrm{kWh}$, was unregulated. By referencing the indicated process characteristics of the established NG phase elongation in the expansion stroke, the combustion time increase as well as the associated decrease in the cylinder excess air ratio $(\alpha)$ are possible reasons for the increase in the incomplete combustion product emission.
\end{abstract}

Keywords: compression ignition engine; conventional fuel injection system; natural gas; energy and emission indicators; fuel injection phase

\section{Introduction}

When comparing autonomous heat engines, modern compression ignition engines (CIEs) are characterised by the highest energy efficiency [1]. This is one of the most important operational indicators, and has a significant influence on the extensive use of these engines in transportation, households, and non-road machines. According to greenhouse gas emission statistics data, CIEs constitute the following parts of the total transport energy balance: $72.1 \%$ of the road vehicle sector, $13.6 \%$ of marine transportation, and $0.5 \%$ of rail transport [2]. Although numerous CIE processes involve heterogeneous fuel mixture combustion across a large temperature inconsistency (at local temperatures up to 2500 to $3000 \mathrm{~K}$ and higher, with an air-fuel equivalent ratio up to 2 to 4 units), a relatively high level of harmful component emission is generated in exhaust gas [1,3,4]. Among the harmful exhaust components, the most dangerous to people's health and fauna are nitrous oxides and particulate matter (PM), which mainly consist of soot [1]. Soot particles of $10 \mu \mathrm{m}$ and less may cause airway diseases such as mesothelioma [3]. CIEs that burn fuel containing sulphur can release sulphuric oxides that are the main cause of acid rain and can cause damage flora [5]. 
Therefore, research on the reduction of harmful emissions into the atmosphere as well as CIE standardisation has become prevalent during recent decades (for example, EN590, EPA, 2012). One of the most widespread technologies is the conversion of CIE for dual-fuel operation and the use of petroleum-derived fuel or either compressed natural gas (CNG) or liquefied natural gas [6-11]. The introduction of NG into the cylinder can be achieved with either high-pressure injection or in combination with liquid fuel spray or carburation with air into air inlet manifold. Owing to the inferior NG auto-ignition properties, the fuel mixture may be ignited with electrical discharge, as with Otto engines [12-14], or by using a pilot fuel portion or high reaction fuel (HRF) [15]. The second method for igniting NG is used most frequently, owing to the easy technological realisation of converting CIE to work with NG, without any need for substantial changes in the CIE structure, while the engine can continue to operate on liquid fuel only [16].

These types of engines, also known as dual-fuel engines, can provide significant improvements in efficiency and emissions [16-25]. For example, in research on a dual-fuel cargo truck engine [26] a decrease in $\mathrm{NO}_{\mathrm{x}}$ of up to six times and decrease in $\mathrm{CO}$ of up to $83 \%$ were observed compared to diesel only operation. The MARPOL 73/79 VI annex standard Tier III norms were achieved in a Wärtsillä company average revolution 20DF ship engine when the engine operated with NG fuel feed, without using secondary emission reduction technologies (such as selective catalytic reduction technology) [24]. Compared to petroleum-based fuel, at least on a theoretical basis, the NG chemical composition contains a carbon/hydrogen ratio that is more favourable for decreasing $\mathrm{CO}_{2}$ emissions responsible for the greenhouse effect by a quarter.

However, serious drawbacks exist when converting a functioning CIE for dual-fuel operation. When using NG greenhouse gas $\mathrm{CO}_{2}$ emissions are reduced because NG, when compared to diesel, has a smaller proportion of carbon atoms, and also the calorific value of NG is $15-25 \%$ higher. Moreover, even when there is an increase in HC emissions from using NG, the overall impact on the greenhouse effect is low, when compared to using diesel only [26]. Also, operation during low load modes results in instability, leading to a reduction in efficiency indicators, and during nominal power load operation and with a large gas fraction of $90 \%$ to $95 \%$ in the fuel balance, this may result in knocking [24,27]. To solve these problems, motor methods are generally used: adjustment of the compression ratio and combustion chamber optimisation $[10,28,29]$, air vortex movement increase in the cylinder [28], and exhaust gas recirculation (EGR) technology [24,26], among others. Research results attest to the conclusion that depending on the operating conditions, the use of NG can increase [24] as well as reduce instances of engine knocking phenomena [27]. For example, in numerical research [24] combustion pressure high frequency pulsation manifests at early and late (by retarding injection timing more than 40 CAD BTDC) pilot fuel injection timing. While at the same time at injection timing from 25 to 40 CAD BTDC pulsations were observed to be minimal. Authors of this publication used a CIE with a conventional fuel injection system. NG had a positive effect and led to a reduction of high frequency pressure amplitude.

HRF characteristic optimisation is a prevalent method, which includes the pilot fuel portion phase, pressure, injection law change, and multiphase injection [30]. The appeal of this method is related to its relative simplicity, which is relevant for operational CIE conversion, with regulation flexibility across a wide speed and load range, and importantly, enables improvements in engine energy efficiency and emission parameters. The majority of research in this area has been based on complex experimental investigation and internal cylinder mathematical modelling, with respect to the injection phase influence on the operation mixture combustion dynamics. For example, in papers [24,25,30-32], the physical mechanism and factors leading to the diesel and gas-environment air engine cylinder chemical kinetics as well as process cylinder dynamics were investigated.

In [30], a one-cylinder (bore $137.2 \mathrm{~mm} /$ stroke $105.1 \mathrm{~mm}$ ) engine with a common rail (CR) fuel injection accumulative system was investigated, and two separate operational mixture combustion physical mechanisms were established, depending on the HRF. The research was conducted on a $25 \%$ partial load and partial part gas phase, with an energy value of co-combustion ratio of NG (CCR NG) 
of approximately $75 \%$. During the late diesel injection time (DIT), which does not exceed $30{ }^{\circ} \mathrm{CA}$ before top dead centre (BTDC), auto-ignition and combustion dynamics were observed, specific to the CIE cycle: $\mathrm{OH}$ radicals were grouped closely with $\mathrm{HRF}$ torch, initiating intensive combustion in accordance with the kinetic mechanism, with a further transition to flame diffusion transfer into the peripheral combustion bowl zones. Therefore, a relatively small increase in the induction period can be observed by advancing the DIT by 4 to $5^{\circ} \mathrm{CA}$ BTDC, and the combustion process is postponed into earlier crankshaft angles; the maximum pressure $P_{\max }$ and maximum combustion temperature $T_{\max }$ increase, which leads to superior $\mathrm{NO}_{\mathrm{x}}$ emission and efficiency $\left(\eta_{e}\right)$. The investigated DIT range of 30 to $50{ }^{\circ} \mathrm{CA}$ BTDC operational mixture thermodynamics becomes insufficient for rapid HRF combustion. The double increase in the induction period surpasses the HRF increase, bringing the combustion process back to TDC. The active auto-ignition $\mathrm{OH}$ centres include a significant part of the combustion chamber (CC) volume, and the fuel gas-air mixture combustion becomes single phase. The local temperature field in the $\mathrm{CC}$ is equalised, thereby reducing the $\mathrm{NO}_{2}$ emissions. Moreover, the reduction not encompassed by the peripheral combustion zones in the CC also leads to a decrease in the emissions of the incomplete combustion products $\mathrm{CO}$ and PM.

Analogous results were found in the DIT range between $50{ }^{\circ} \mathrm{CA}$ BTDC and $5{ }^{\circ} \mathrm{CA}$ after top dead centre (ATDC) in a high-revolution (bore $85 \mathrm{~mm} /$ stroke $90 \mathrm{~mm}$ ) engine with a common rail system [1]. Furthermore, the influence of the DIT on the energy efficiency and emissions was established. The authors of the paper have expanded their research by changing the HRF injection pressure in the range of 500 to 1000 bar, optimising the DIT speed, and separating the HRF into component parts, in combination with pressure optimisation. It was established that HRF injection during the early phases is an effective method for improving dual-fuel engine energy efficiency and emissions. A maritime purpose single-cylinder average rpm CIE, Wärtsillä 20DF (bore $200 \mathrm{~mm} / \mathrm{stroke} 280 \mathrm{~mm}$ ), with a CR system, was also studied [24].

This research was conducted to establish the HRF distribution and structure, as well as influence of the thermodynamic properties in a compression process on the HRF auto-ignition and fuel mixture combustion process. The experimental research was conducted with medium, nominal engine loads at constant revolutions; the HRF injection pressure was adjusted within the range of 1300 to 2100 bar; the DIT ranged from 15 to $50{ }^{\circ} \mathrm{CA}$ BTDC. It was established that, in the DIT range of up to $30{ }^{\circ} \mathrm{CA}$ BTDC, the HRF combustion reaction potency, as assessed by the localised HRF equivalence ratio, was high, which is in accordance with the research results. A predominant $\beta$ value range of 0.2 to 0.8 determines the comparatively short ignition delay of 10 to $17^{\circ} \mathrm{CA}$ BTDC and intense combustion. Later, the DIT is accompanied by a noticeable $\beta=0.2$ to 0.8 part reduction, causing a homogenous operational mixture combustion close to the TDC.

Combustion obtains "soft" characteristics, equalising the localised temperature fields and reducing emissions. Moreover, it was established that the fuel mixture thermodynamic parameter changes in the cylinder (by advancing the inlet valve closing phase) are no less effective than the increased HRF ignition delay period. It is important to note that, during this event, the DIT range is significantly reduced: in the conducted experiment from $45^{\circ} \mathrm{CA}$ BTDC up to $32^{\circ} \mathrm{CA}$ BTDC, emissions were reduced to or below the MARPOL 73/78 Tier III standard established values. Similar results were obtained in an experiment with a six-cylinder engine (Bore $11.2 \mathrm{~mm} /$ Stroke $13.2 \mathrm{~mm}$ ) [33] with a CR system, by advancing the DIT up to $32{ }^{\circ} \mathrm{CA}$ BTDC (CCR NG 90\%), and low load mode emissions were reduced. As opposed to the experimental results from $[23,27,28,30,34]$, in which engine parameter deterioration resulted in an increase in hydrocarbon emissions, a reduction in the energy efficiency was observed.

A short overview of the research demonstrates the significance of improving modern engine energy efficiency and emission parameters, changing their operation to NG. However, the separate CIE category conversion to NG operation faces several difficulties. Firstly, problems include models with traditional mechanical fuel injection systems, which exhibit the characteristic of a limited DIT range change and a substantially lower diesel fuel injection pressure compared to the CR system. However, numerous operational CIEs exist with traditional mechanical fuel injection systems. Therefore, 
the objective of reducing environmental pollution is inseparable from modernising current generation CIEs to work with NG.

Moreover, it should be noted that most research has concentrated on separate speed and load engine operation mode experiments. However, when a fixed $C C R N G$ gas component exists, there is a lack of data regarding the fuel mixture composition in wide and rational engine work mode ranges, as well as rational dual-fuel distribution in real-life operational range modes. Work that evaluates diesel reading changes under operational conditions has passive properties as a rule, without the realisation of experiments $[4,26,35]$. This is because of operational health and safety regulations for parameter changes, which limit fast-acting processes.

This paper presents the results from a team of Klaipeda University and Vilnius Gediminas Technical University scientists. The research object was a high-revolution four-stroke engine with a conventional fuel injection system, converted for operation with dual-fuel feed diesel and compressed NG.

The research objectives were as follows:

- Rational estimation of the dual D-NG fuel composition, justifying solutions in accordance with energy efficiency, emissions, and reliability values, while the engine is operating in a wide range of modes.

- The influence of fuel injection timing on the characteristics of the conventional injection fuel system engine.

- The evaluation of rational directions of a converted dual-fuel CIE operation process, with the purpose of establishing a higher level of energy efficiency and environmentally friendly effectiveness.

\section{Experimental Methodology}

\subsection{General Description of Dual-Fuel Engine}

Direct injection high revolution four cylinder turbocharged CIE tests were performed at the Internal Combustion Engines Laboratory of the Automobile Transport Department, Faculty of Transport Engineering, Vilnius Gediminas Technical University. A turbocharged 1.9 litre engine with an electronically controlled BOSCH VP37 distribution-type fuel pump and turbocharger was used for the tests. The EGR system was disabled during the tests. Diesel injection timing was controlled using Pulse-Width-Modulation (PWM), by forming electronic control signals for the fuel pump (Figure 1). The main CIE parameters are listed in Table 1.

Table 1. Engine specification.

\begin{tabular}{cc}
\hline Displacement (L) & $\mathbf{1 . 8 9 6}$ \\
\hline Bore $\times$ stroke $(\mathrm{mm})$ & $79.5 \times 95.5$ \\
Power $(\mathrm{kW}) /$ speed $(\mathrm{rpm})$ & $66 / 4000$ \\
Torque $(\mathrm{Nm}) /$ speed $(\mathrm{rpm})$ & $180 / 2000-2500$ \\
Cooling type & Water cooling \\
Fuel supply system & Direct injection \\
Cylinders & 4 in line \\
Compression ratio & $19.5: 1$ \\
Aspiration & Turbocharge \\
\hline
\end{tabular}

\subsection{Test Bench}

The scheme of the laboratory equipment is illustrated in Figure 1. A KI-5543 engine brake stand was used for the load $M_{B}$ and crankshaft speed determination. The torque measurement error was $\pm 1.23 \mathrm{Nm}$. The hourly fuel consumption $B_{f}$ was measured by SK-5000 electronic scales and a stopwatch, and the accuracy of the $B_{f}$ determination was $0.5 \%$.

The NG fuel was measured by a Coriolis-type mass flow meter. The fuel flow meter was a RHEONIK RHM 015 (see Figure 1 pos. 25), connected into the high-pressure fuel supply system before 
the gas reducer, which reduced the gas to a pressure of 1.5 bar. The flow meter measuring range was 0.004 to $0.6 \mathrm{~kg} / \mathrm{min}$ with a high measurement accuracy of $\pm 0.10 \%$.

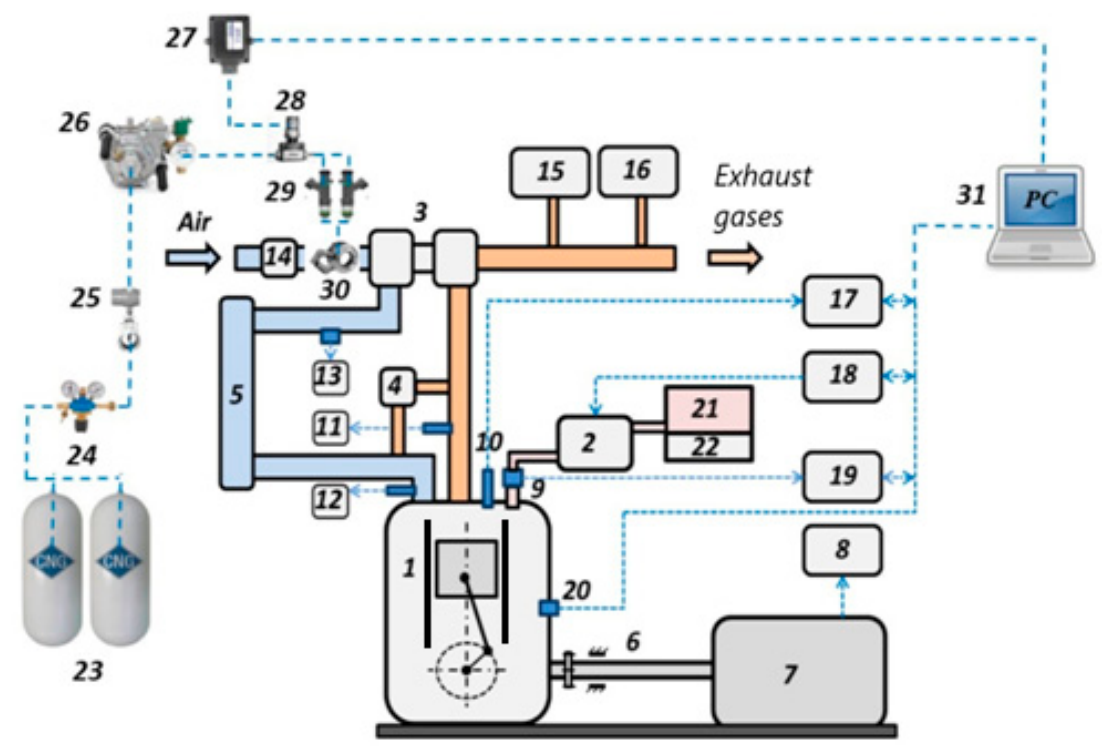

Figure 1. Scheme of the engine testing equipment: 1: engine; 2: high-pressure fuel pump; 3: turbocharger; 4: EGR valve; 5: air cooler; 6: connecting shaft; 7 : engine load stand; 8 : engine torque and rotational speed recording equipment; 9: fuel injection timing sensor; 10: cylinder pressure sensor; 11: exhaust gas temperature meter; 12: intake air temperature meter; 13: intake air pressure meter; 14: air mass meter; 15: exhaust gas analyser; 16: opacity analyser; 17: cylinder pressure recording equipment; 18: fuel injection timing control equipment (PWM); 19: fuel injection timing recording equipment; 20: crankshaft position sensor; 21: fuel tank; 22: fuel consumption measuring equipment; 23 : CNG tank; 24: pressure regulation valve; 25: gas flow meter; 26: pressure reducer; 27: ECU; 28: gas metering valve; 29: gas injectors; 30: air and gas mixer; 31: computer.

\subsection{Exhaust Gas Emission Measurement Equipment}

The pollutants in the exhaust gas were measured using several gas analysers: AVL DiCom 4000 (AVL, Austria) (Table 2) and HORIBA PG-250 (HORIBA, Japan)(Table 3), TESTO 350 Maritime (TESTO, Indonesia) (for $\mathrm{CO}, \mathrm{CO}_{2}, \mathrm{HC}$, and $\mathrm{NO}_{\mathrm{x}}$ ) (Table 4), and AVL DiCom 4000 and MDO-2 LON (MAHA, Germany) (for absorption coefficient K-value) (Table 5). The HORIBA PG-250, TESTO $350 \mathrm{M}$, and MDO-2LON were used as measurement value control units to ensure the accuracy of the measurement results. The main equipment for the exhaust gas analysis was the AVL DiGas 4000/AVL DiCom 4000 (AVL, Austria).

Table 2. Measurement range and resolution of AVL DiCom 4000 gas analyser.

\begin{tabular}{ccc}
\hline Parameter & Measurement Range & Measurement Accuracy \\
\hline Nitrous oxides $\left(\mathrm{NO}_{\mathbf{x}}\right)$ & $0-5000 \mathrm{ppm}(\mathrm{vol})$. & $1 \mathrm{ppm}$ \\
Hydrocarbons $(\mathrm{HC})$ & $0-20,000 \mathrm{ppm}($ vol. $)$ & $1 \mathrm{ppm}$ \\
Carbon monoxide $(\mathrm{CO})$ & $0-10 \%$ (vol.) & $0.01 \%$ (vol.) \\
Carbon dioxide $\left(\mathrm{CO}_{2}\right)$ & $0-20 \%($ vol. $)$ & $0.1 \%$ (vol.) \\
Oxygen $\left(\mathrm{O}_{2}\right)$ & $0-25 \%($ vol. $)$ & $0.01 \%$ (vol.) \\
Absorption $(\mathrm{K}-\mathrm{value})$ & $0-99.99 \mathrm{~m}^{-1}$ & $0.01 \mathrm{~m}^{-1}$ \\
Lub. oil temperature & $0-150{ }^{\circ} \mathrm{C}$ & $1^{\circ} \mathrm{C}$ \\
\hline
\end{tabular}

HORIBA PG-250 exhaust gas analyser measurement range and resolution.

This equipment contains a gas preparation block, which cools down the gases and thus removes condensate $\left(\mathrm{H}_{2} \mathrm{O}\right)$ surplus that may accumulate during combustion. During analysis, the quality of the outlet gases is established. The complex exhaust gas analyser TESTO 350 Maritime measurement range and resolution are given in Table 4. 
Table 3. Measurement range and resolution of HORIBA PG-250 analyser.

\begin{tabular}{ccc}
\hline Emission Component & Measurement Range & Measurement Accuracy \\
\hline $\mathrm{CO}$ & $0-5000 \mathrm{ppm}$ & $\pm 1 \%$ F.S. \\
$\mathrm{CO}_{2}$ & $0-20 \mathrm{vol} . \%$ & $\pm 1 \%$ F.S. \\
$\mathrm{SO}_{2}$ & $0-3000 \mathrm{ppm}$ & $\pm 1 \mathrm{ppm}$ F.S. \\
$\mathrm{NO}_{\mathrm{x}}$ & $0-2500 \mathrm{ppm}$ & $\pm 1 \mathrm{ppm}$ F.S. \\
$\mathrm{O}_{2}$ & $0-25 \%$ & $\pm 1 \mathrm{ppm}$ F.S. \\
\hline
\end{tabular}

Table 4. Measurement range and resolution of TESTO 350M analyser.

\begin{tabular}{ccc}
\hline Emission Component & Measurement Range & Measurement Accuracy \\
\hline $\mathrm{CO}$ & $0-5000 \mathrm{ppm}$ & $\pm 5 \%$ F.S. \\
$\mathrm{CO}_{2}$ & $0-50 \%$ & $\pm 0.3 \mathrm{vol} \%+1 \%$ F.S. \\
$\mathrm{NO}_{\mathrm{x}}$ & $0-5000 \mathrm{ppm}$ & $\pm 5 \mathrm{ppm}(0-99 \mathrm{ppm}) ; \pm 5 \%$ F.S. \\
$\mathrm{SO}_{2}$ & $0-5000 \mathrm{ppm}$ & $(+100-+500 \mathrm{ppm})$ \\
$\mathrm{O}_{2}$ & $0-25 \%$ & $\pm 5 \%$ F.S. \\
\hline
\end{tabular}

Exhaust gas opacity analyser MDO-2 LON measurement range and accuracy.

Table 5. Measurement range and resolution of MDO-2 LON analyser.

\begin{tabular}{ccc}
\hline Measurement Parameter & Measurement Range & Measurement Accuracy \\
\hline Opacity & $0-100 \%$ & $\pm 2 \%$ F.S. \\
Absorption (K-value) & $0-99.99 \mathrm{~m}^{-1}$ & $\pm 2 \%$ F.S. \\
\hline
\end{tabular}

The in-cylinder pressure $\left(P_{c y l}\right)$ was recorded by an AVL GH13P piezo-sensor (sensitivity $16 \mathrm{pC} / \mathrm{bar}$, linearity of FSO $\leq \pm 0,3 \%$ ), which was integrated into the preheating plug and recorded using an AVL DiTEST DPM 800 amplifier (input range 6000 pC, signal ratio $1 \mathrm{mV} / \mathrm{pC}$, overall error complete temperature range $1 \%$ ) and LabView Real-Time equipment. The intake air mass flow meter was measured by a BOSCH HFM 5 with an accuracy of $2 \%$. The intake manifold pressure was measured with a Delta OHM HD 2304.0 pressure gauge. A TP704-2BAI sensor device with an error of \pm 0.0002 $\mathrm{MPa}$ was mounted ahead of the intake manifold. The exhaust and intake gases temperature meter K-type thermocouple (accuracy $\pm 1.5^{\circ} \mathrm{C}$ ) was used.

\subsection{Fuel Specification}

Two fuel types were used during the experiment: liquid and gas (Table 6). During the dual-fuel mode, standard diesel fuel (EN 590) and standard compressed NG (ISO 6976:1995) were used.

Table 6. Fuel properties.

\begin{tabular}{ccc}
\hline Fuel type & Natural gas & Diesel \\
\hline Density $\left(\mathrm{kg} / \mathrm{m}^{3}\right)$ & 0.74 & 829.0 \\
Cetane number & - & 49 \\
$H_{U}(\mathrm{MJ} / \mathrm{kg})$ & 51.7 & 42.8 \\
Viscosity $\left(\mathrm{cSt} 40^{\circ} \mathrm{C}\right)$ & - & 1.485 \\
$\mathrm{H} / \mathrm{C}$ ratio & - & 1.907 \\
Component $(\%$ vol. $)$ & Methane: 91.97 & Carbon: 86.0 \\
& Ethane: 5.75 & Hydrogen: 13.6 \\
& Propane: 1.30 & Oxygen: 0.4 \\
& Butane: 0.281 & \\
& Nitrogen: 0.562 & \\
& Carbon dioxide: 0.0 & \\
\hline
\end{tabular}

\subsection{Basis for Numerical Research}

The CNIDI (Central Diesel Research Institute, St. Petersburg, Russia) mathematical model from the TEPLM software package has been used in order to conduct analysis of experimentally obtained 
indicated process diagrams [36], which used a closed thermodynamic cycle energy balance model, evaluating the heat transfer through the cylinder walls. Initial values for the software calculations included the dual-fuel cycle portion $\left(q_{c}\right)$ and lower heating value $H_{L}$, while the chemical composition $(\mathrm{C}, \mathrm{H}, \mathrm{O})$ was established using the following formula:

$$
q_{c}=\frac{q_{c_{D}} \cdot H_{L_{D}}+q_{c_{N G}} \cdot H_{L_{N G}}}{H_{L}} .
$$

where,

$q_{c}$ : Overall fuel consumption per cycle, g/cycle;

$q_{c_{D}}$ : Diesel fuel consumption per cycle, g/cycle;

$q_{c_{N G}}:$ NG fuel consumption per cycle, g/cycle;

$H_{L_{D}}$ : Lower heating value of diesel fuel, $\mathrm{MJ} / \mathrm{kg}$;

$H_{L_{N G}}$ : Lower heating value of $\mathrm{NG}, \mathrm{MJ} / \mathrm{kg}$.

$H_{L}$, the lower heating value of the fuel $(\mathrm{MJ} / \mathrm{kg}$ ) was calculated by the Mendeleev equation [36]:

$$
H_{L}=337.5 \cdot \mathrm{C}+1025 \cdot H-108.3 \cdot O \text {, }
$$

where,

$$
\begin{aligned}
& C=C_{D} \cdot(100-C C R N G)+C_{N G} \cdot C C R N G, \\
& H=H_{D} \cdot(100-C C R N G)+H_{N G} \cdot C C R N G, \\
& O=O_{D} \cdot(100-C C R N G)+O_{N G} \cdot C C R N G, \\
& C C R N G=\frac{q_{c_{N G}} \cdot H_{L_{N G}}}{q_{c_{N G}} \cdot H_{L_{N G}}+q_{c_{D}} \cdot H_{L_{D}}} \cdot 100 \% .
\end{aligned}
$$

where,

CCR NG: Co-combustion ratio of natural gas, $\%$

$C_{D}$ : Element carbon composition in diesel fuel

$C_{N G}$ : Element carbon composition in NG.

Energy efficiency parameters:

The indicated efficiency $\left(\eta_{i}\right)$ could be established using the following formula:

$$
\eta_{i}=\frac{3.6 \cdot P_{e}}{H_{L D} \cdot G_{f D}+H_{L N G} \cdot G_{f N G}} .
$$

where, $H_{L D}$ and $H_{L N G}$ : lover heat values of diesel fuel and NG, respectively, MJ $/ \mathrm{kg} ; B_{f D}$ and $B_{f N G}$ : diesel fuel and NG consumption, respectively, $\mathrm{kg} / \mathrm{h}$.

The brake thermal efficiency could be established using the classical expression $\eta_{e}=\eta_{i} \cdot \eta_{m}$, where $\eta_{m}$ is the mechanical resistance coefficient established using the combined mechanical engine losses $P_{m}$, and $P_{m}$ could be determined from the experimental indicator diagrams.

\subsection{Experiment Execution Plan}

The experimental engine efficiency and emission research was conducted with a wide range of loads $\left(P_{m e}\right)$ and $\mathrm{rpm}(n)$, as well as various HRF injection timing angles $\left(\varphi_{\text {inj }}\right)$ (see Table 7 ). In every mode, characterised by different combinations $\left(P_{m e(D)}, n, \varphi_{i n j}\right)$, the engine parameters were measured using diesel only (D), and dual D and NG fuel: D60/NG40, D40/NG60, and D20/NG80 (here, the numbers following " $\mathrm{D}$ " and "NG" correspond to the diesel and NG percentage parts of the total energy balance). The engine load modes were named in the following manner: $P_{m e}=5.97$ bar, high load mode (HLM); $P_{m e}=3.98$ bar, medium load mode (MLD); and $P_{m e}=1.98$ bar, low load mode (LLM). 
Table 7. Experiment execution plan

\begin{tabular}{|c|c|c|c|c|c|c|c|c|c|c|c|c|c|}
\hline & \multirow[b]{2}{*}{$\varphi_{i n j}$} & \multicolumn{4}{|c|}{$n=2500 \mathrm{~min}^{-1} \mathrm{D} / \mathrm{GD}$} & \multicolumn{4}{|c|}{$n=2000 \mathrm{~min}^{-1} \mathrm{D} / \mathrm{GD}$} & \multicolumn{4}{|c|}{$n=1500 \mathrm{~min}^{-1} \mathrm{D} / \mathrm{GD}$} \\
\hline & & D & D60/G40 & D40/G60 & D20/G80 & D & D60/G40 & D40/G60 & D20/G80 & D & D60/G40 & D40/G60 & D20/G80 \\
\hline \multirow{3}{*}{$P_{m e}=0.597 \mathrm{MPa}$} & -1 & & & & & $x$ & $x$ & $x$ & $x$ & & & & \\
\hline & -7 & & & & & $x$ & $x$ & $x$ & $x$ & & & & \\
\hline & -13 & & & & & $x$ & $x$ & $x$ & $x$ & & & & \\
\hline \multirow{3}{*}{$P_{m e}=0.398 \mathrm{MPa}$} & -1 & $x$ & $x$ & $x$ & $x$ & $x$ & $x$ & $x$ & $x$ & & & & \\
\hline & -7 & $x$ & $x$ & $x$ & $x$ & $x$ & $x$ & $x$ & $x$ & & & & \\
\hline & -13 & $x$ & $x$ & $x$ & $x$ & $x$ & $x$ & $x$ & $x$ & & & & \\
\hline \multirow{3}{*}{$P_{m e}=0.198 \mathrm{MPa}$} & -1 & & & & & $x$ & $x$ & $x$ & $x$ & $x$ & $x$ & $x$ & $x$ \\
\hline & -7 & & & & & $x$ & $x$ & $x$ & $x$ & $x$ & $x$ & $x$ & $x$ \\
\hline & -13 & & & & & $X$ & $x$ & $x$ & $x$ & $x$ & $x$ & $x$ & $x$ \\
\hline
\end{tabular}

Note: The engine parameters were investigated in the following ranges: $\varphi_{i n j}=1 ; 4 ; 7 ; 10 ; 13{ }^{\circ} \mathrm{CA} \mathrm{BTDC}$; the provided results are in the range: $\varphi_{i n j}=1 ; 7 ; 13{ }^{\circ} \mathrm{CA}$ BTDC. $\mathrm{X}$ : investigated parameters. 
For every load mode energy efficiency value, the emission and indicated parameters were registered at least three times, with further average calculations and rough error removal using statistical methods (MAthWorks-Matlab, Microsoft Excel). The indicator diagram pressure data arrays were established as the averages of 100 registered indicator diagrams.

\section{Research Results and Discussion}

The conversion of a CIE for operation with NG fuel feed encompasses the evaluation of energy efficiency, emissions, and reliability values (cylinder used, piston group detailed mechanical load ratio criteria, and maximum cylinder pressure $P_{\max }$ ).

\subsection{Changes in Energy Efficiency}

The effective $\eta_{e}$ and indicated $\eta_{i}$ efficiency were used as the energy efficiency parameters. Changes in the parameter $\eta_{e}$ when increasing $C C R N G$ in different load and rpm modes $\left(P_{m e}\right)$, and the injection timing $\varphi_{\text {inj }}$ range results are provided as well (see Figure 2).

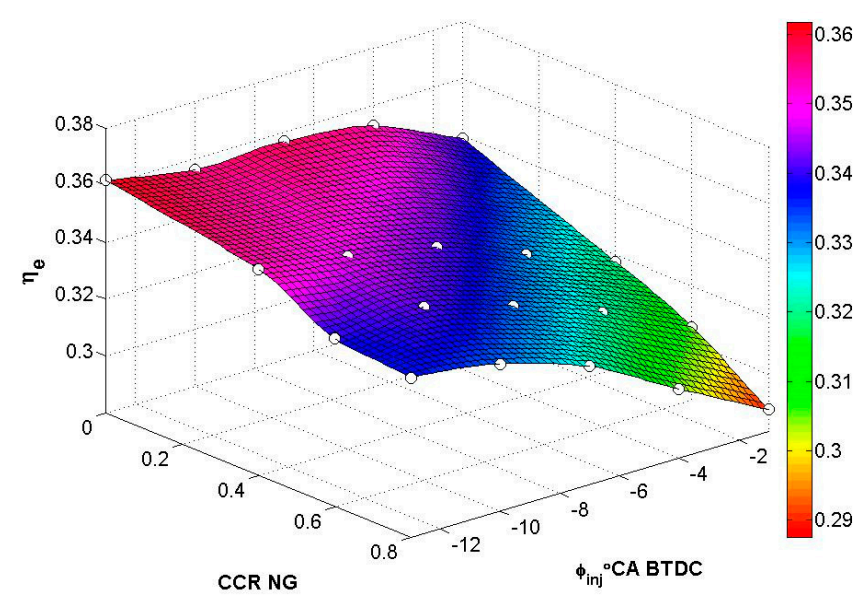

(a)

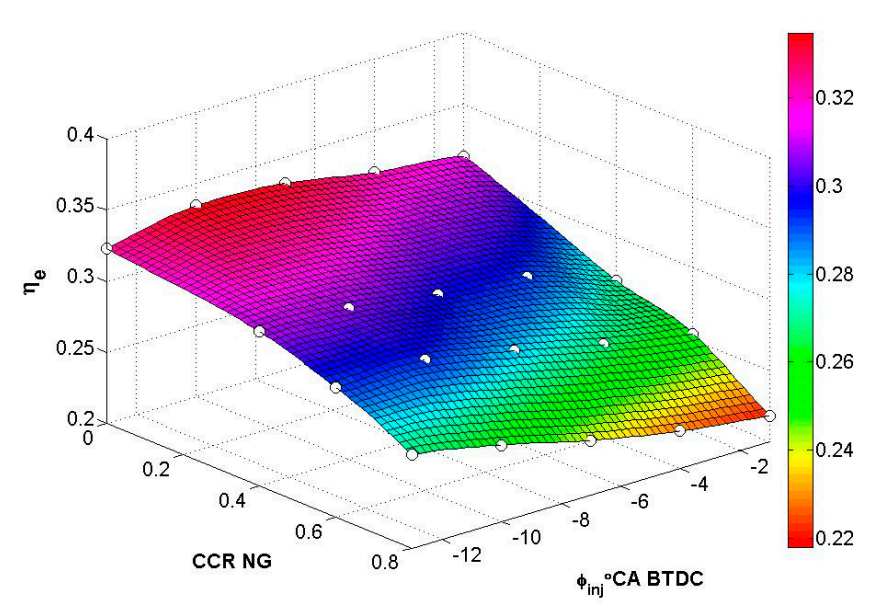

(b)

Figure 2. Cont. 


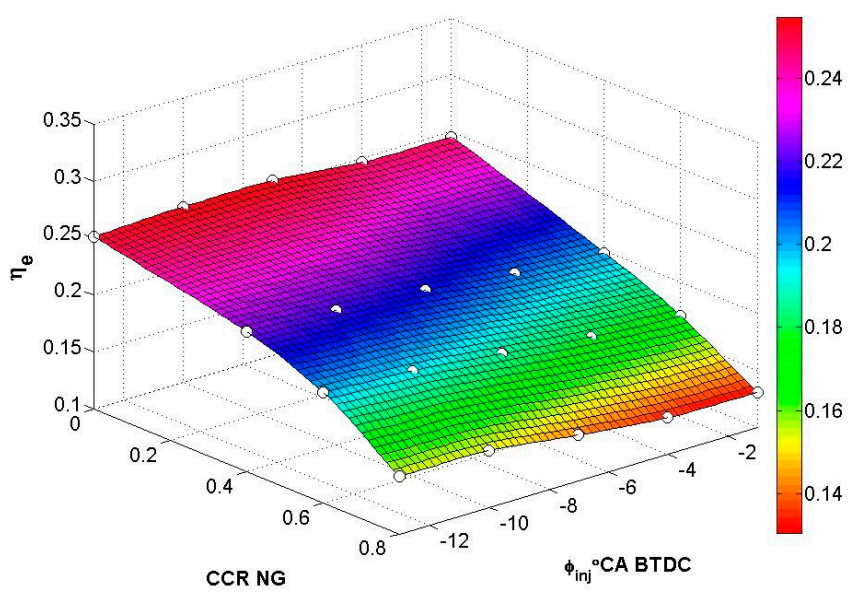

(c)

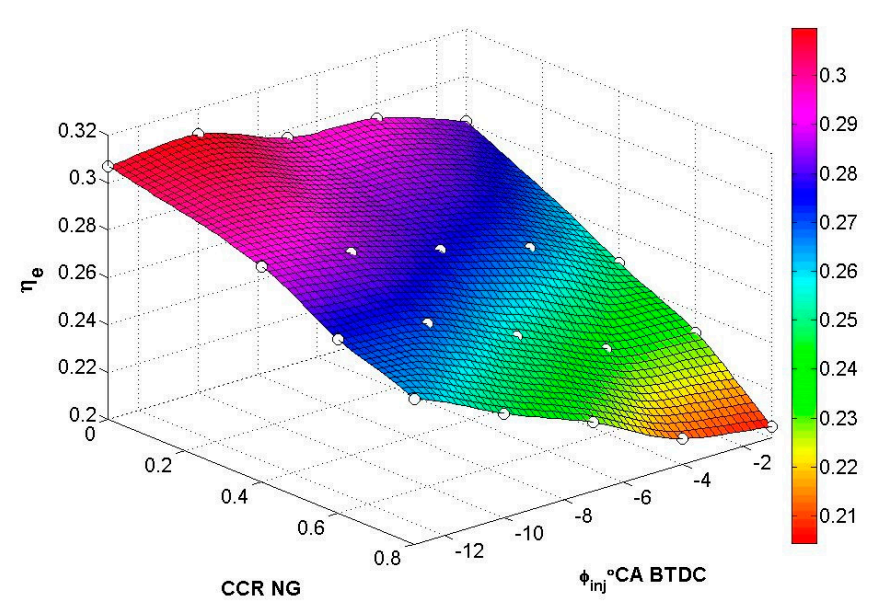

(d)

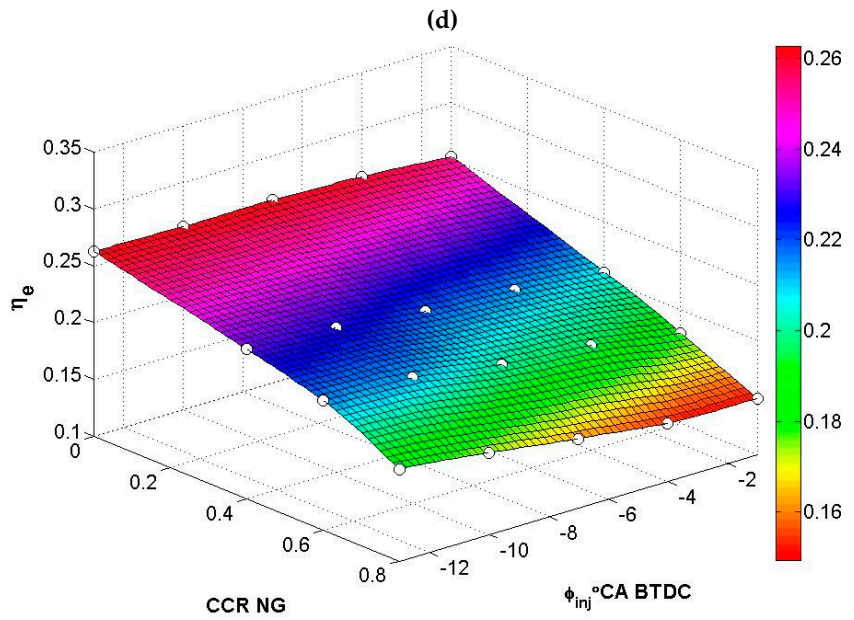

(e)

Figure 2. Influence of CCR NG and $\varphi_{i n j}\left(\phi_{i n j}\right)$ on engine $\eta_{e}$ at (a) HLM, $n=2000 \mathrm{~min}^{-1}$; (b) MLM, $\mathrm{n}=2000 \mathrm{~min}^{-1}$; (c) LLM, $n=2000 \mathrm{~min}^{-1}$; (d) MLM, $n=2500 \mathrm{~min}^{-1}$; (e) LLM, $n=1500 \mathrm{~min}^{-1}$. The experimental data are denoted by dots in the graph. 
It should be noted that the obtained dependencies $\eta_{e}=f\left(P_{m e}, \varphi_{i n j}, C C R N G\right)$ are qualitatively and quantitatively identical to those of an engine operating in the investigated revolution range of $n=1500 \mathrm{~min}^{-1}, n=2000 \mathrm{~min}^{-1}, n=2500 \mathrm{~min}^{-1}$ (see Figure 2).

Based on this change in the CCR, the engine parameters were specified as $n=2000 \mathrm{~min}^{-1}$.

The load characteristics at $n=1500 \mathrm{~min}^{-1}$ and $n=2500 \mathrm{~min}^{-1}$ data were limited, only disclosing their specific features. However, the CCR NG quantitative influence did differ strongly for different load modes.

Operating in a mode close to the nominal engine load $P_{m e}=5.98$ bar CCR NG, the increase in the influence on the $\eta_{e}$ parameter was minimal: a $0.8 \%$ to $1.8 \% \eta_{e}$ decrease for every CCR NG increase of $10 \%$. The range top limit values were obtained with relatively low process dynamics, at $\varphi_{i n j}=1$ to $4{ }^{\circ} \mathrm{CA}$ BTDC; lower values are specific to processes with high work process dynamics at $\varphi_{\text {inj }}=10$ to $13^{\circ} \mathrm{CA} \mathrm{BTDC}$ (see Figure 3).

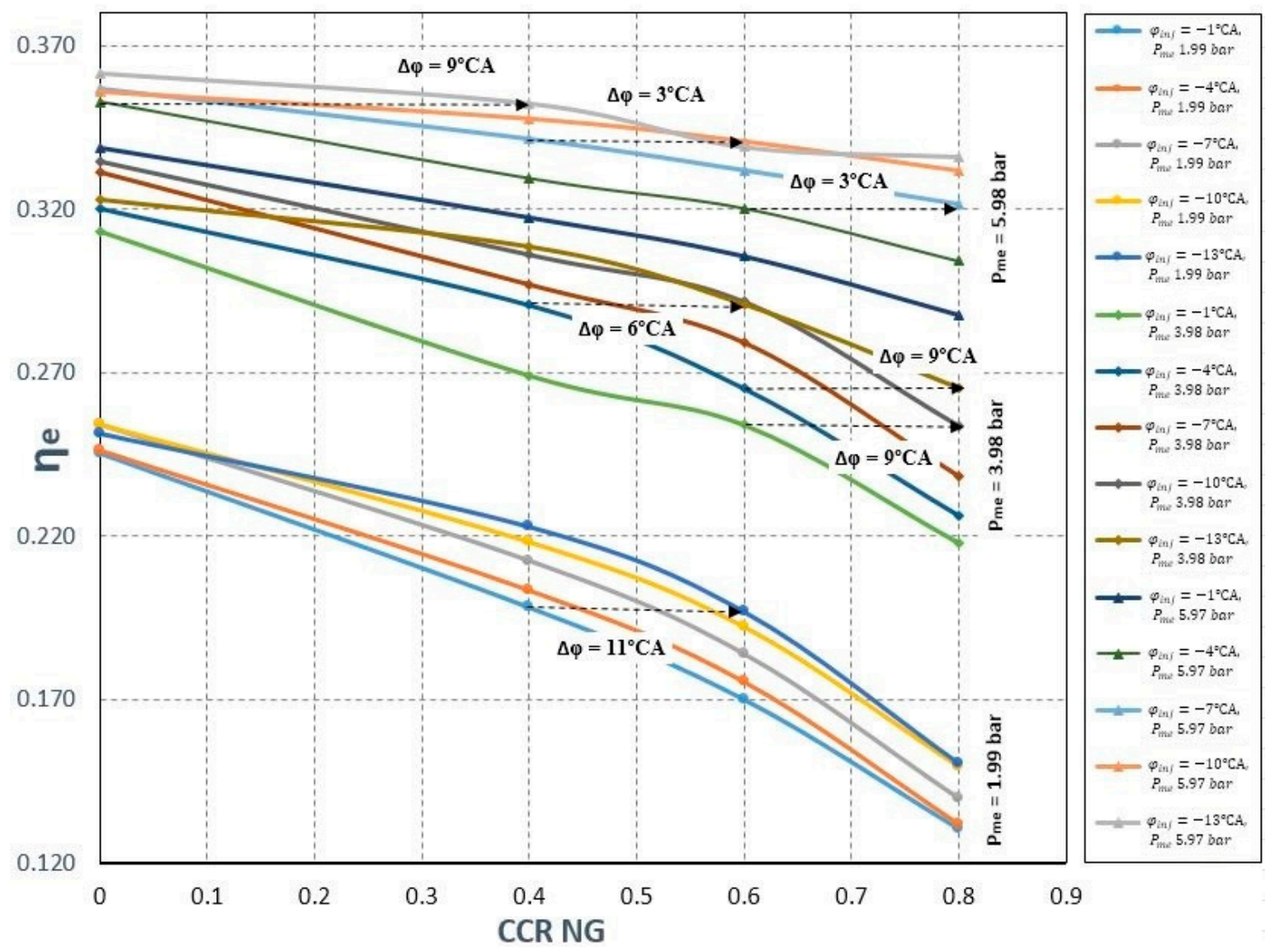

Figure 3. Influence of $C C R N G$ portion increase on diesel engine $\eta_{e}$.

The analysed $\varphi_{i n j}$ change was evaluated as one of the most technologically simple measures, capable of improving the engine parameters for dual-fuel operation. Moreover, an experiment on the changes in $\varphi_{i n j}$ within the range of 1 to $13^{\circ} \mathrm{CA}$ BTDC was conducted to expand the obtained results for engines with different dynamic characteristics $\left(P_{\max }\right.$, pressure increase for maximum speed $(d P / d \varphi)_{\max }$ average speed $(d P / d \varphi)_{\text {mid }}$, and pressure increase for $\left.(\lambda)\right)$.

The MLM $P_{m e}=3.98$ bar parameter $\eta_{e}$ decreased for every CCR NG increase of $10 \%$, making up $2.5 \%$ to $3.5 \%$, and for the LLM $P_{m e}=1.99$ bar from $4.7 \%$ to $6.0 \%$. It is possible to adjust the parameter $\varphi_{i n j}$ to improve $\eta_{e}$ for operation with NG in different load modes, and $P_{m e}$ differs significantly. When the engine is operating in the $\operatorname{HLM} \varphi_{\text {inj }}$ advancement $\left(\Delta \phi_{\text {inj }}\right)$ to $3{ }^{\circ} \mathrm{CA} \mathrm{BTDC}$, compensating for the negative effect of an increase in the CCR increase on $\eta_{e}$ (Figure 3). 
Overall, it is rational that for every CCR NG increase of $20 \%$, there should be an advancement of $\varphi_{\text {inj }}\left(\Delta \phi_{i n j}\right)$ by $3^{\circ} \mathrm{CA}$ BTDC. The obtained results are specific to the investigated $\varphi_{\text {inj }}$ range, which means that it is applicable for engine models with different operational process dynamics: in the investigated object, the pressure increase $P_{\max } / P_{c}$ was changed (where $P_{c}$ is the final compression pressure) within the range from 0.9 to 1.8 .

In the MDL mode, the influence of the $P_{m e}=3.98$ bar parameter $\varphi_{i n j}$ on $\eta_{e}$ decreased. In order to compensate for the $\eta_{e}$ decrease with the engine operating on NG, it is necessary to advance $\varphi_{i n j}$ $\left(\Delta \phi_{\text {inj }}\right)$ to 3 to $6{ }^{\circ} \mathrm{CA}$ for every $20 \%$ increase in CCR NG: the lower limit values are consistent with a low dynamics process. For the LLM $P_{m e}=1.99$ bar, the injection timing $\varphi_{i n j}$ must be advanced $\left(\Delta \phi_{i n j}\right)$ to 9 to $12{ }^{\circ} \mathrm{CA}$ or even more.

The adjustment of $\varphi_{i n j}$ for improving $\eta_{e}$ is inseparable from the necessity to control the operation process dynamic parameters, including the maximum cycle pressure, in order to avoid mechanical overloading of the engine. The overall tendency of the investigated engine load $P_{\max }$ is that a decrease in $P_{\max }$ occurs with an increase in CCR NG (see Figure 4). It is known that the size of $P_{\max }$ is determined by the heat release $Q_{P_{\max }}$ at the maximum pressure phase $\varphi_{P_{\max }}$ [37-40]. The size is mainly formed by the heat released during the first kinetic phase, which is influenced by the auto-ignition delay period $\varphi_{i}$. A decrease in the amount of fuel injected through $\varphi_{i}$ or in the period of injection $\varphi_{i}$ ensures a decrease in $P_{\max }$ [41-43]. The $P_{\max }$ dependence on the CCR NG portion variable is nonlinear: at a $C C R N G$ increase of up to $0.4, P_{\max }$ changed only slightly; however, when the CCR NG increased to a larger portion than 0.4 and up to 0.8 , the decrease in $P_{\max }$ reached 10 to 15 bar (see Figure 4 ).

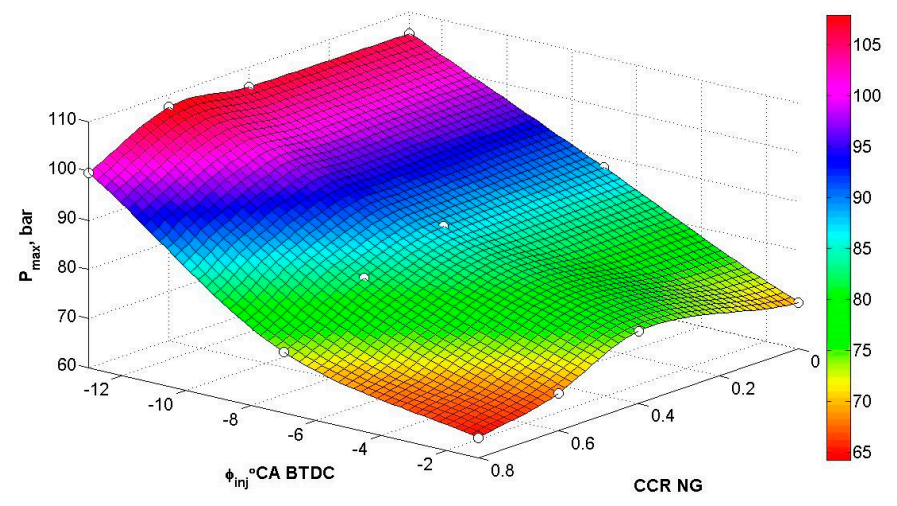

(a)

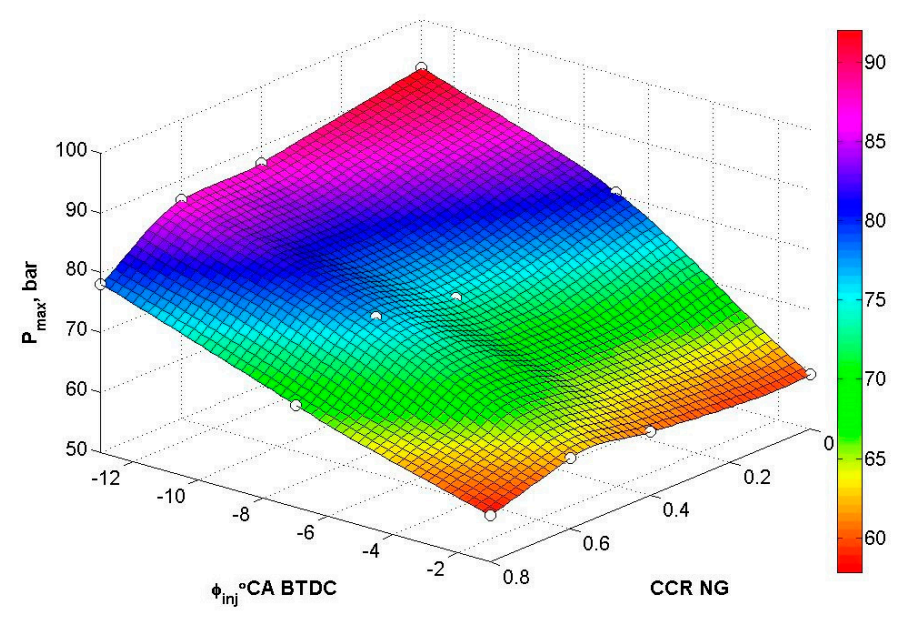

(b)

Figure 4. Cont. 


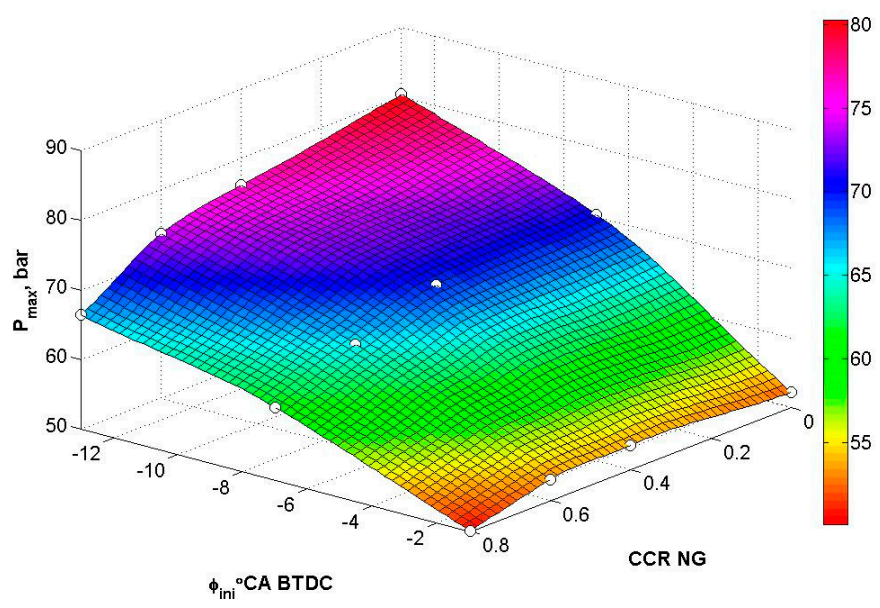

(c)

Figure 4. Injection timing $\varphi_{\text {inj }}$ influence on maximum cycle pressure $P_{\max }\left(n=2000 \mathrm{~min}^{-1}\right):(\mathbf{a}) \mathrm{HLM}$; (b) MLM; (c) LLM. The dots in the graph represent the experimental data.

Therefore, it is appropriate to increase the CCR NG and compensate for the $\eta_{e}$ losses with an increase in $\varphi_{i n j}$. Thus, in order to evaluate the changes in $P_{\max }$ for CIE conversion for operation with NG fuel feed it is necessary to use different portions of NG, such as CCR NG 0 to 0.2 and 0 to 0.4 . Figure 5 provides the engine indicator diagrams with the speed of heat release characteristics $d Q / d \varphi$.

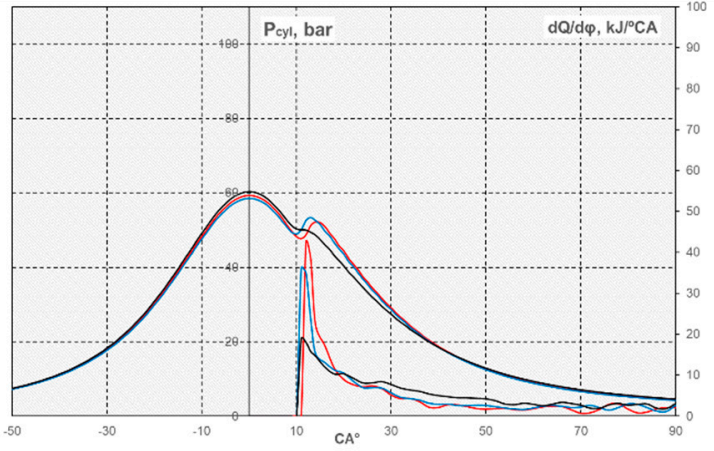

$\rightarrow D-D 60$ NGG4O $-D 20$ NNG80

(a)

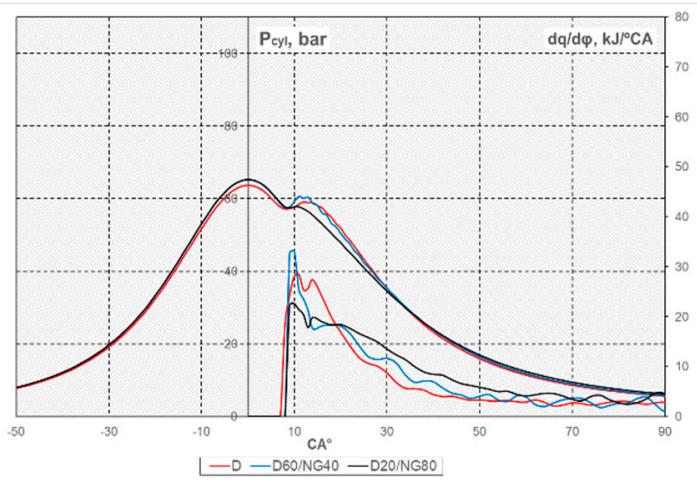

(c)

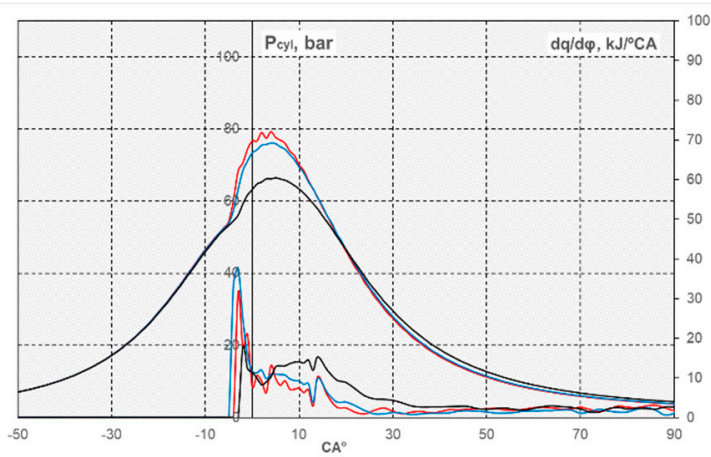

(b)

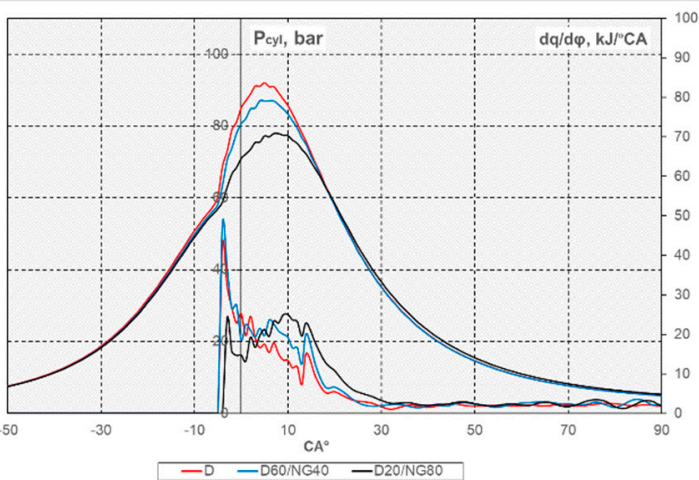

(d)

Figure 5. Cont. 


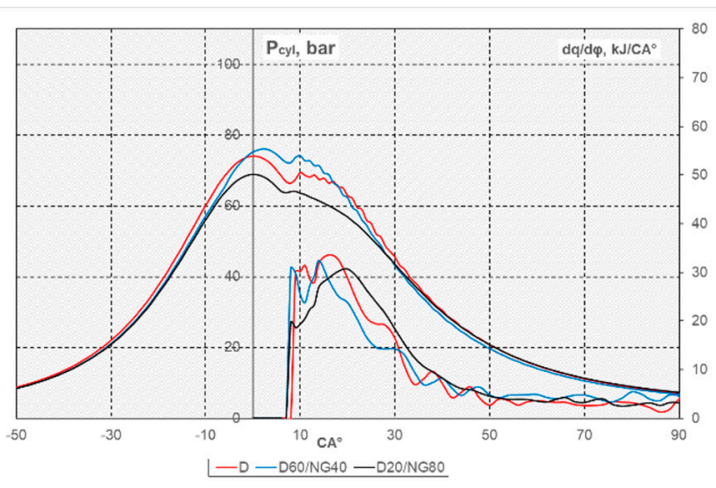

(e)

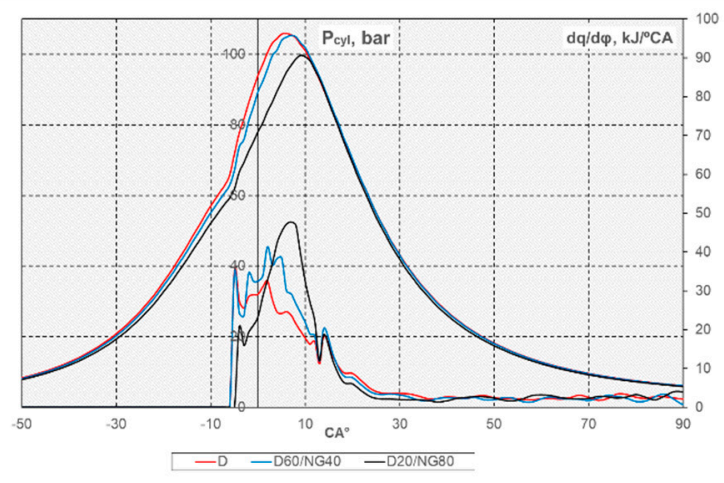

(f)

Figure 5. Combustion process indicator diagrams and heat release dynamics $d Q / d \varphi$ for different $\varphi_{i n j}\left(\varphi_{i n j}=-1\right.$ and $\left.-13^{\circ} \mathrm{CA}\right),\left(n=2000 \mathrm{~min}^{-1}\right):(\mathbf{a})$ and $(\mathbf{b})$ correspond to LLM; (c) and (d) correspond to MLM; (e) and (f) correspond to HLM.

For every engine load mode, the diesel auto-ignition phase for $\varphi_{i n j}-i d e m$ did not change in the CCR NG portion range from 0 to 0.8 . The ignition delay period $\varphi_{i}$ also did not change for $\varphi_{i}=8 \pm 1^{\circ} \mathrm{CA}$ in all investigated $\varphi_{i n j}$. Overall, the decrease in $P_{\max }$ can be linked to the changes in the heat release dynamics when the CCR NG is increased. A decrease in the diesel portion decreases the heat release in the heterogeneous combustion kinetics phase, and increases the total energy balance part of the NG volume specific combustion part $[18,23,44]$. The combustion process moves towards an expansion stroke, and therefore the decrease in $P_{\max }$ occurs in parallel with the deterioration in $\eta_{e}$.

The advancement of the injection timing $\varphi_{i n j}$ moves the combustion process towards TDC, compensating for the changes in $\eta_{e}$ relating to the CCR NG increase. However, the $\varphi_{i n j}$ advancement in engines with conventional fuel injection systems exhibits limited capabilities in the aforementioned range. One method for improving the $\eta_{e}$ characteristics is accelerating the combustion process in the second (main) phase, which forms the energy efficiency indicators of the cycle. In order to achieve this, the cylinder air load is increased; moreover, the fuel portion vortex movement degree is increased by using different technological methods, such as incorporating fuel additives [42,43].

In the HLM, in which the CCR NG constitutes 0.2 , to compensate for the deterioration in $\eta_{e}, \varphi_{i n j}$ is advanced to $3^{\circ} \mathrm{CA} \mathrm{BTDC}$, and the maximum cycle pressure is increased to 7 to 10 bar (see Figure 4). In the MLM, the $\varphi_{\text {inj }}$ advancement to $6^{\circ} \mathrm{CA}$ BTDC leads to an increase in $P_{\max }$ of up to 15 to 25 bar: the result is that $P_{\max }$ is at a larger pressure than that obtained by using diesel only (CCR NG $=0$ ).

The LLM $P_{\max }$ can reach 20 to 25 bar. Although $P_{\max }$ is lower during the medium and low load modes compared to the modes that are closer to the nominal engine load, and engine operation in the HLM only occurs for a limited time, a meaningful increase can significantly decrease the engine reliability. Therefore, it is not considered as rational for practical use. A CCR NG increase for the LLM up to 0.4 , together with a $\varphi_{i n j}$ advancement to $6^{\circ} \mathrm{CA}$, can lead to an increase in $P_{\max }$ to 15 to 25 bar.

During the MLM, the $P_{\max }$ increase can reach up to 30 bar and more. It should be noted that changes in $P_{\max }$ are established when the engine is operating with diesel fuel feed in a stationary state of $\varphi_{i n j}=1$ to $4{ }^{\circ} \mathrm{CA}$ BTDC, or low process dynamics. When the system is in a higher state of $\varphi_{i n j}=7$ to $13^{\circ} \mathrm{CA}$ BTDC or in a more dynamic DE operation state, the advancement of $\varphi_{\text {inj }}$ becomes irrational: for a small $\eta_{e}$ restoration effect, a large increase in $P_{\max }$ is necessary.

Overall, it should be stated that application of the $\varphi_{i n j}$ advancement to compensate for the decrease in energy efficiency when the engine is operating in the dual-fuel mode is limited during the HLM and portions of the CCR NG from 0 to 0.4 .

The exchange of diesel for NG and the use of NG in different load modes are essentially expanded by applying the $\varphi_{i n j}$ advancement method, when there is also a decrease of approximately $3 \%$. The LLM CCR NG is expanded to $40 \%$, while the MLM possible CCR NG application reaches $20 \%$ when decreases 
of $34 \%$ and $6 \%$ occur, respectively. An increase occurs when operating with diesel fuel equal to 7 bar, which remains unchanged.

\subsection{Emission}

The engine emission evaluation is directly related to the engine purpose. Vehicle engines are regulated by international standards throughout the entire range of harmful emissions: $\mathrm{NO}_{\mathrm{x}}, \mathrm{CO}, \mathrm{C}_{\mathrm{n}} \mathrm{H}_{\mathrm{m}}$, and $\mathrm{SO}_{\mathrm{x}}$, as well as PM [45-48]. Moreover, marine-purpose DEs are regulated by MARPOL 73/78 convention Annex VI [49] for $\mathrm{NO}_{x}$ and $\mathrm{SO}_{\mathrm{x}}$ emissions. However, as opposed to DEs for other purposes, marine power plants are also regulated by the decision of the International Maritime Organization to limit greenhouse gas $\mathrm{CO}_{2}$ emissions [50]. Therefore, it is correct for the evaluation of converted dual-fuel engine emissions to be conducted in accordance with their purpose.

\subsubsection{Nitrous oxides}

The majority of research has pointed out that CIE conversion for operation with NG fuel feed fundamentally decreases $\mathrm{NO}_{x}$ emissions, owing to the equalisation of the combustion temperature field in the cylinder and decrease in high-temperature zones [45-47,50]. The results obtained from this research agree with this tendency. The effects of the $\mathrm{NO}_{\mathrm{x}}$ emission decrease with an increase in the CCR are nonlinear - the maximum effect in the investigated options was detected in the CCR NG > $40 \%$ range. The $\mathrm{NO}_{x}$ mainly decreased in the LLM $P_{m e}=1.99$ bar.

Moreover, depending on the stationary $\varphi_{i n j}$ value while operating on diesel only, for every $C C R$ NG increase of $10 \%$, the $\mathrm{NO}_{\mathrm{x}}$ emissions decreased by $7 \%$ to $3 \%$ in the HLM, and $9 \%$ to $10 \%$ in the MLM and LLM (earlier values of $\varphi_{\text {inj }}$ exhibited lower changes in $\mathrm{NO}_{\mathrm{x}}$ emissions). With this manner of exchanging diesel for $\mathrm{NG}$, the $\mathrm{NO}_{\mathrm{x}}$ decrease constitutes approximately $65 \%$ in the HLM, and a decrease in $\mathrm{NO}_{\mathrm{x}}$ of $90 \%$ to $95 \%$ can be reached in the MLM and LLM (see Figure 6).

However, the CCR NG increase is followed by a decrease in $\eta_{e}$ of up to $20 \%$ in the MLM and $45 \%$ in the LLM. It is obvious that the changes in $\eta_{e}$ and $\mathrm{NO}_{\mathrm{x}}$ must be coordinated, for example, by applying the $\varphi_{i n j}$ advancement method (see Figure 6).

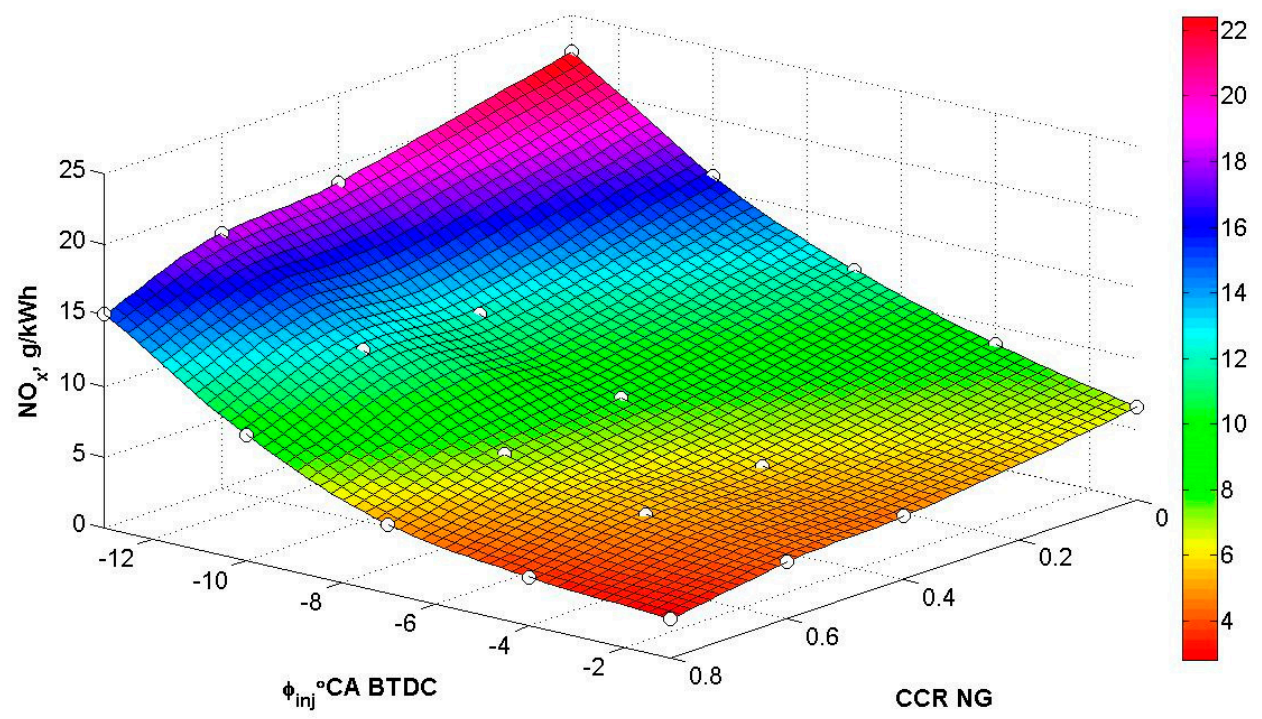

(a)

Figure 6. Cont. 


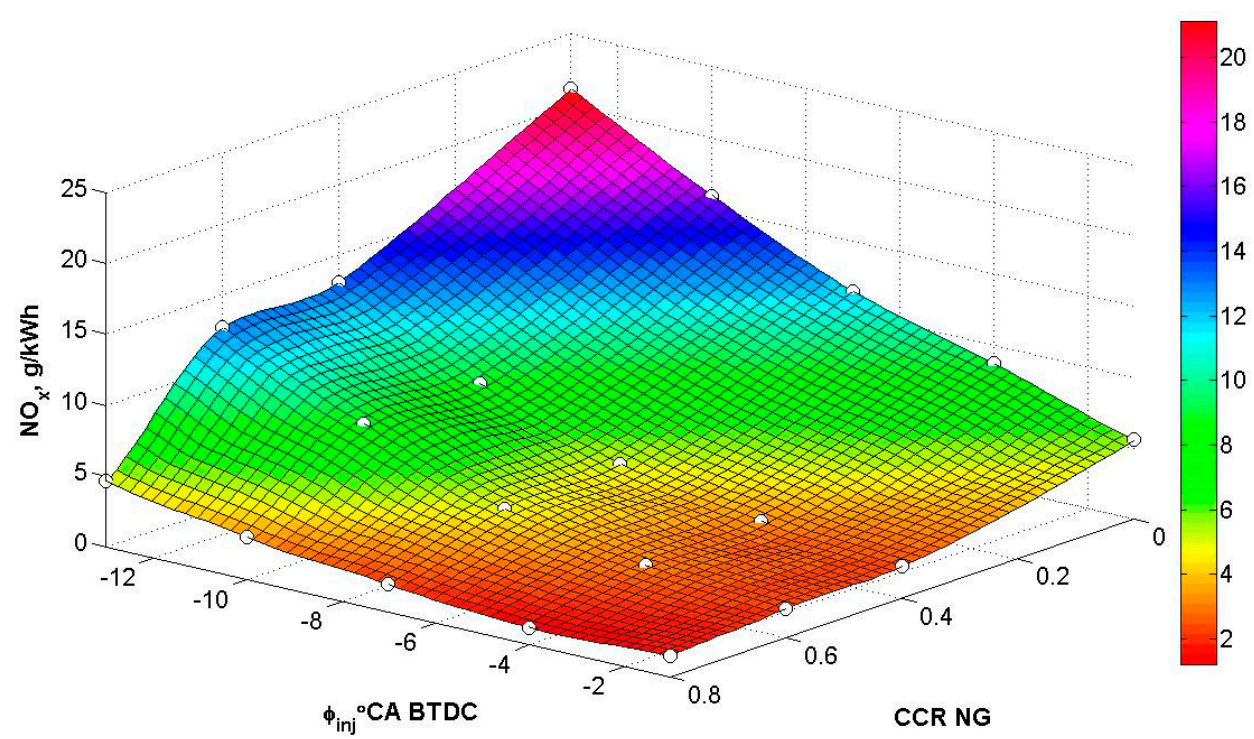

(b)

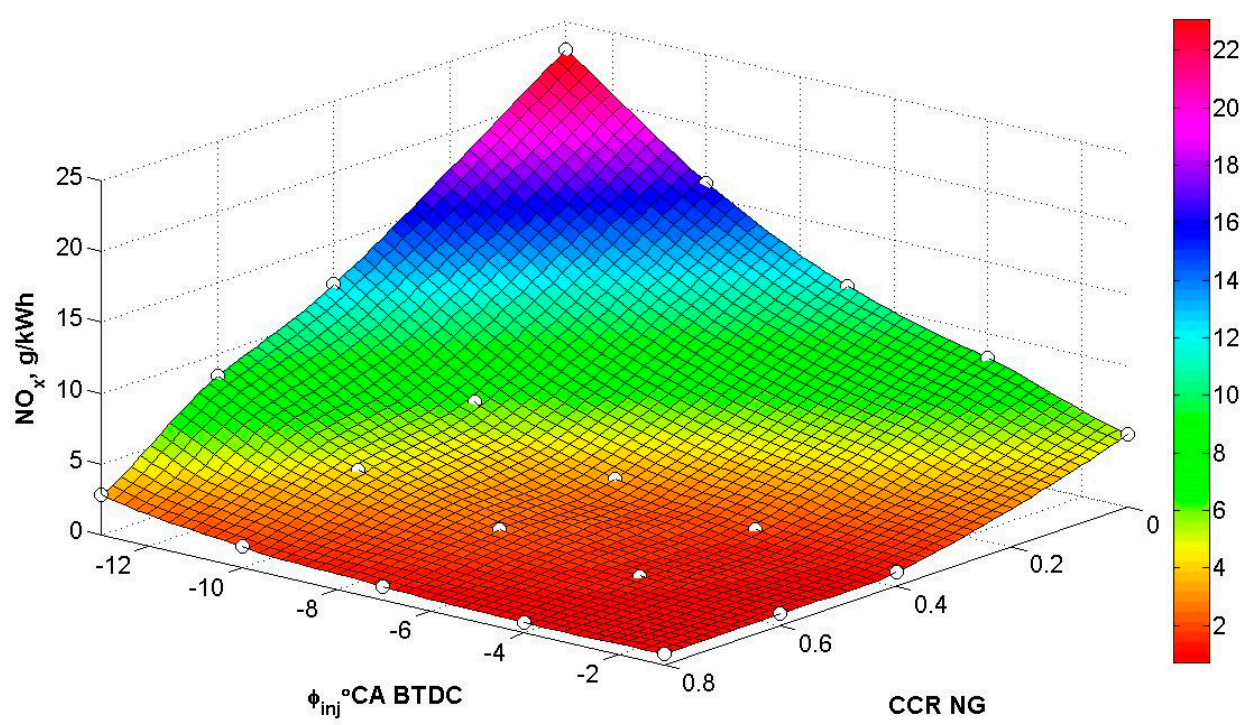

(c)

Figure 6. Influence of dual-fuel CCR NG portion and $\varphi_{\text {inj }}$ on $\mathrm{NO}_{\mathrm{x}}$ emissions $\left(n=2000 \mathrm{~min}^{-1}\right)$ : (a) HLM; (b) MLM; (c) LLM. The dots in the graph represent the experimental data.

A CCR NG increase to 0.2 in the HLM was implemented practically without a significant decrease in the energy efficiency; therefore, even without the use of $\varphi_{i n j}$ advancement, the $\mathrm{NO}_{\mathrm{x}}$ emissions decreased. When increasing the CCR NG portion up to 0.4 , it is rational to use a limited $\varphi_{\text {inj }}$ advancement solution, which will ensure a certain amount of $\eta_{e}$ and $\mathrm{NO}_{\mathrm{x}}$ reduction. For example, in the HLM, a $\varphi_{i n j}$ advancement to $3{ }^{\circ} \mathrm{CA}$ BTDC instead of $6^{\circ} \mathrm{CA}$ BTDC ensured a reduction in $\eta_{e}$ and $\mathrm{NO}_{\mathrm{x}}$ of $3 \%$ and $0.9 \mathrm{~g} / \mathrm{kWh}$, respectively. Without changing $\varphi_{\text {inj }}, \eta_{e}$ was reduced by $6.5 \%$, and the $\mathrm{NO}_{\mathrm{x}}$ emissions were reduced by 1.2 to $1.7 \mathrm{~g} / \mathrm{kWh}$ or $35 \%$ compared to the engine operating on diesel only.

In the MLM, a partial deterioration of the $\eta_{e}$ compensation with a change in $\varphi_{i n j}$ ensured a $\mathrm{NO}_{\mathrm{x}}$ decrease of 0.7 to $1.1 \mathrm{~g} / \mathrm{kWh}$ or approximately $15 \%$. In the LLM, exchanging 0.2 of diesel with NG, without $\varphi_{i n j}$ adjustment, a reduction in $\mathrm{NO}_{x}$ emissions of 2 to $3.3 \mathrm{~g} / \mathrm{kWh}$ or $50 \%$ was achieved. 


\subsubsection{Carbon monoxide}

According to various sources, the conversion of a CIE for dual-fuel operation is related to a significant increase in harmful partial combustion components, such as $\mathrm{CO}$ and HC emissions [45-48]. During the experiment, it was determined that when a portion of CCR NG of 0.8 was reached, the $C O$ emissions increased 8 to 30 times in the HLM from the base level of $0.5 \mathrm{~g} / \mathrm{kWh}, 20$ to 30 times in the MLM from approximately $1 \mathrm{~g} / \mathrm{kWh}$, and 10 to 20 times in the LLM from approximately 2 to $6 \mathrm{~g} / \mathrm{kWh}$, during different operation dynamics (see Figure 7).

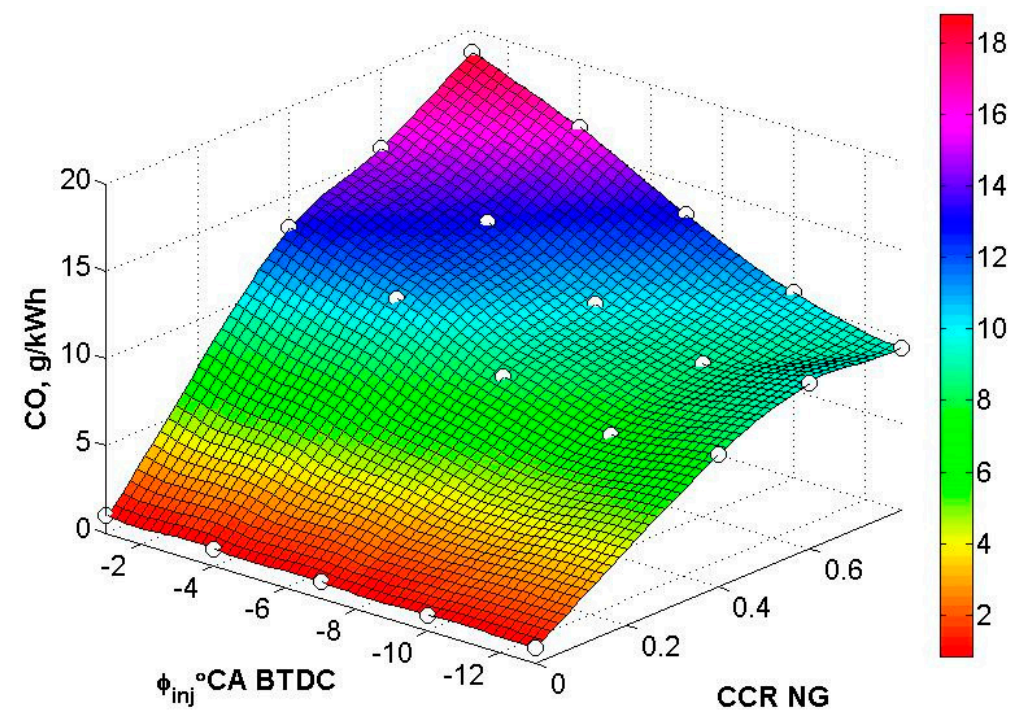

(a)

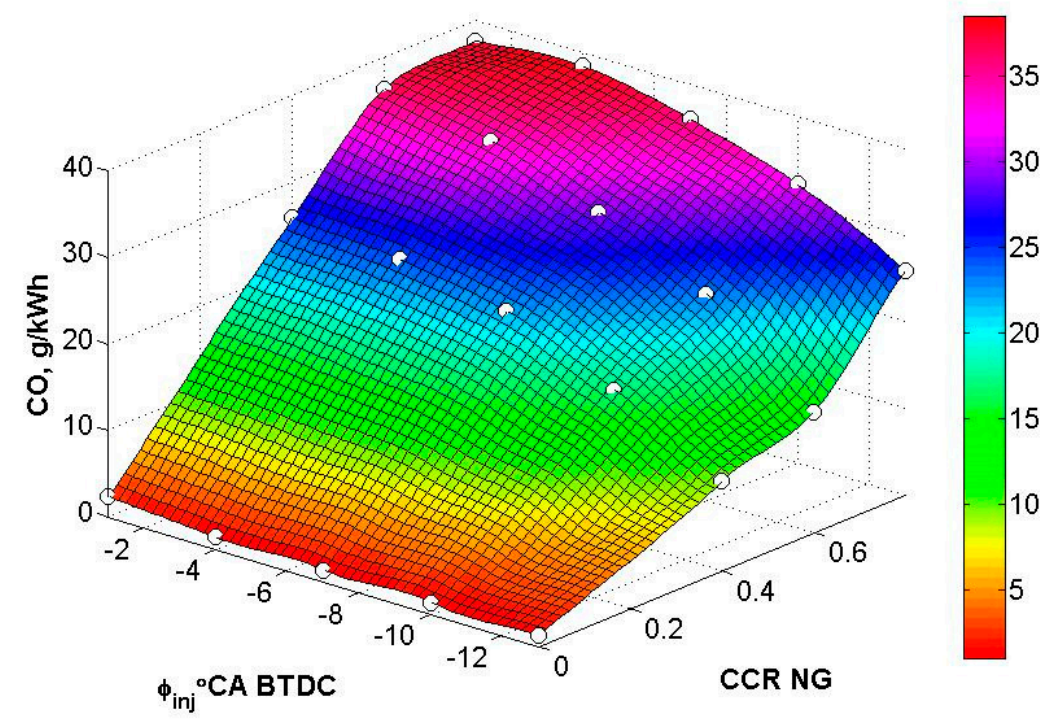

(b)

Figure 7. Cont. 


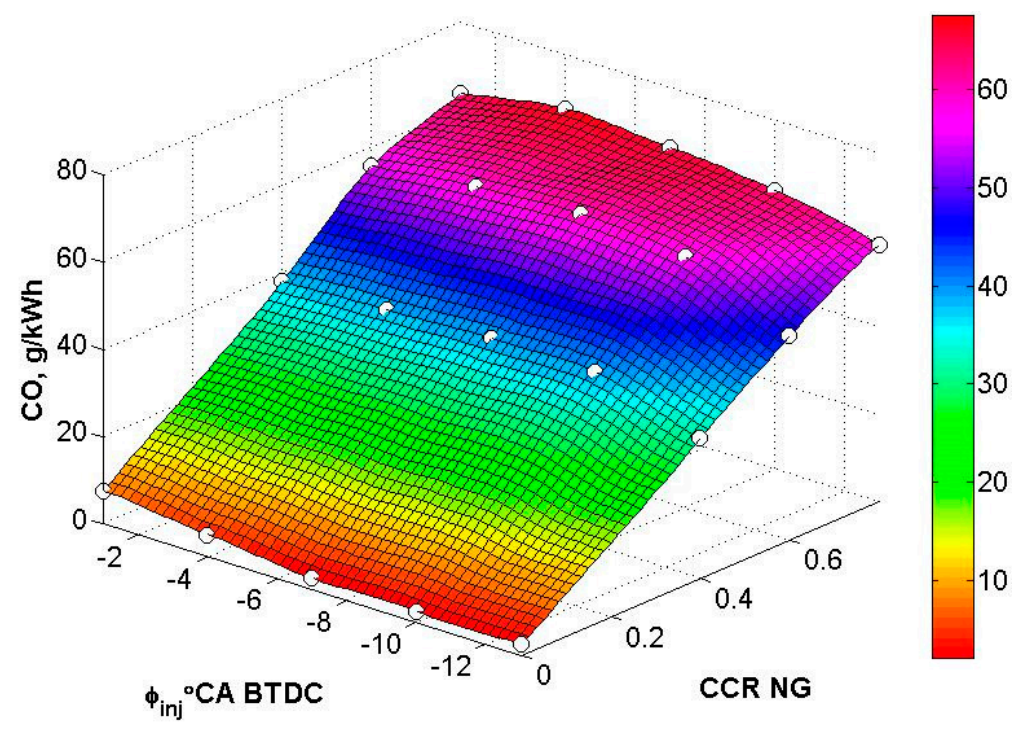

(c)

Figure 7. Influence of dual-fuel CCR NG portion and $\varphi_{\text {inj }}$ on CO emissions $\left(n=2000 \mathrm{~min}^{-1}\right):(\mathbf{a}) \mathrm{HLM}$; (b) MLM; (c) LLM. The dots in the graph represent the experimental data.

In the investigated range, $\varphi_{i n j}$ advancement becomes an ineffective measure for $\mathrm{CO}$ emission control. Overall, for CCR NG 0.2 and 0.4 portions, an increase in CO emissions could be detected in the HLM of 3 to $5 \mathrm{~g} / \mathrm{kWh}$ and 5.5 to $10 \mathrm{~g} / \mathrm{kWh}$, and in the MLM, with CCR NG 0.2, an increase occurred for 7 to $10 \mathrm{~g} / \mathrm{kWh}$.

\subsubsection{Hydrocarbons}

No less intensive is the HC increase when the engine is operating on NG (see Figure 8).

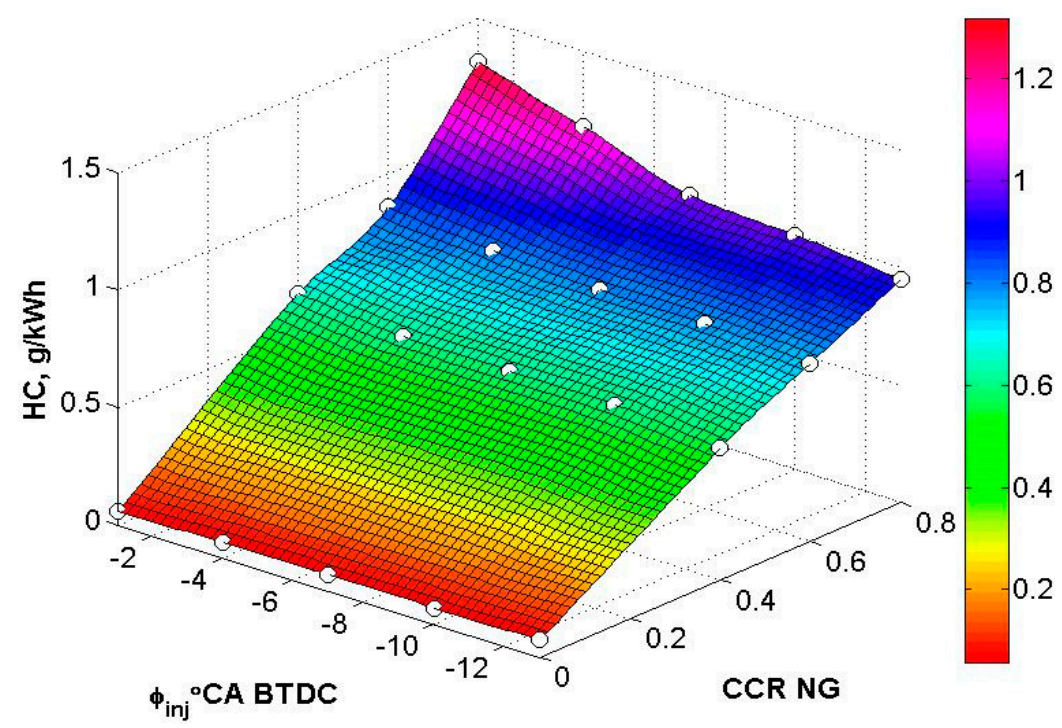

(a)

Figure 8. Cont. 


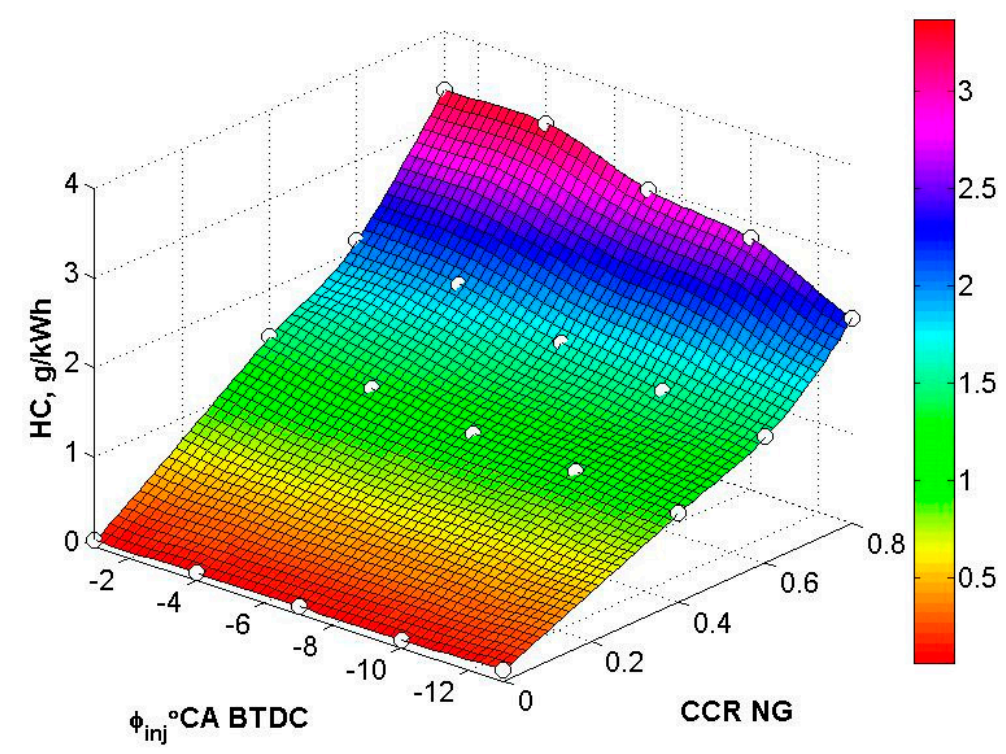

(b)

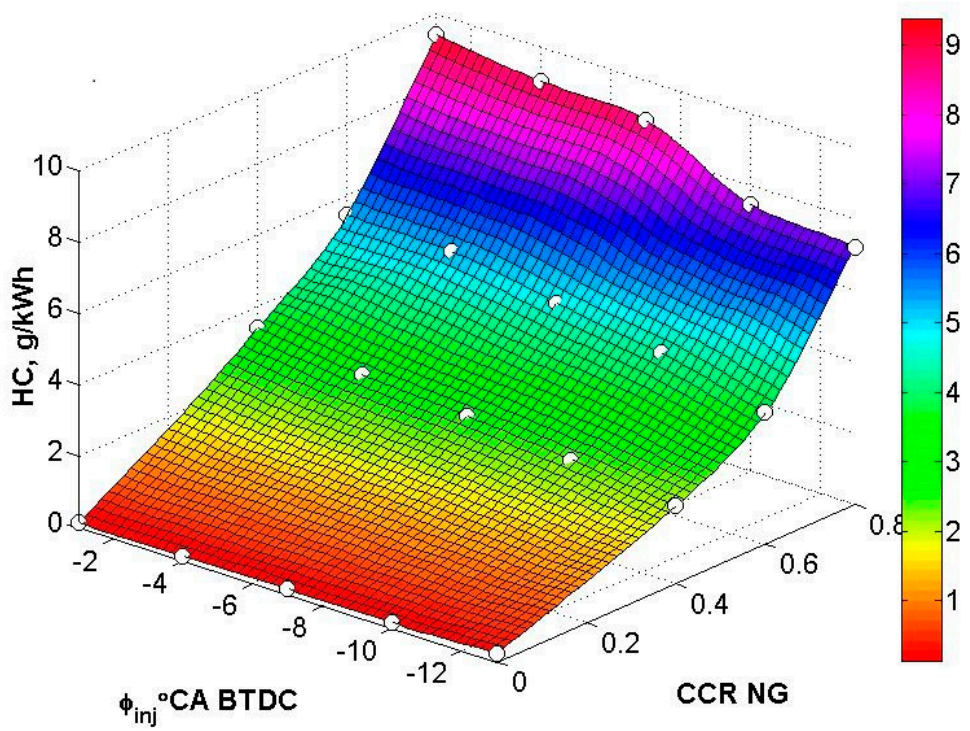

(c)

Figure 8. Influence of dual-fuel CCR NG portion and $\varphi_{i n j}$ on HC emissions $\left(n=2000 \mathrm{~min}^{-1}\right)$ : (a) HLM; (b) MLM; (c) LLM. The dots in the graph represent the experimental data.

The HC emissions increased when the engine load was increased, and the influence of the $\varphi_{\text {in } j}$ advancement was not significant. In the HLM, for every CCR NG portion increase of 0.1 , the HC emission increase constituted approximately $0.1 \mathrm{~g} / \mathrm{kWh}$; when the CCR NG was in the range of 0.6 to 0.8 , the HC emissions increased by 0.15 to $0.4 \mathrm{~g} / \mathrm{kWh}$. In the MLM, for an analogous CCR NG portion, the $\mathrm{HC}$ emissions increase constituted 0.4 to $0.6 \mathrm{~g} / \mathrm{kWh}$ and 0.7 to $1.5 \mathrm{~g} / \mathrm{kWh}$, respectively; for the LLM, the values were 1 to $1.5 \mathrm{~g} / \mathrm{kWh}$ and 2.5 to $3.0 \mathrm{~g} / \mathrm{kWh}$.

\subsubsection{Carbon Dioxide}

Greenhouse gas $\mathrm{CO}_{2}$ emissions from internal combustion engines are dependent on two factors: the carbon $C$ in the fuel chemical composition and fuel consumption $[45,46,51]$. Compared to diesel, the NG chemical composition has a C part of $75 \%$ versus $85 \%$ to $86 \%$. Thus, engine conversion for 
operating on NG at the same mass portion results in a decrease in fuel consumption and therefore reduced $\mathrm{CO}_{2}$ emissions.

During the experiment, a decrease in $\mathrm{CO}_{2}$ was only achieved for the HLM $P_{m e}=5.98$ bar in the entire CCR NG portion range from 0 to 0.8 (see Figure 9).

Moreover, the $\varphi_{i n j}$ advancement reduced the $\mathrm{CO}_{2}$ emissions in the $C C R N G$ portion range from 0 to 0.8 : when $\varphi_{i n j}=-1{ }^{\circ} \mathrm{CA} \mathrm{BTDC}$, the $\mathrm{CO}_{2}$ emissions decreased by $9 \%$, for $\varphi_{i n j}=-13^{\circ} \mathrm{CA}$ BTDC, the decrease could reach $16 \%$. For the MLM and LLM, the increased $\mathrm{CO}_{2}$ emissions led to a deterioration in energy efficiency. Overall, in the mode of $P_{m e}=3.98$ bar for a range up to a CCR NG portion of 0.6 , the increase in $\mathrm{CO}_{2}$ emissions practically remained unchanged, and with a further increase in the $C C R$ NG up to 0.6 to 0.8 in the LLM, the $\mathrm{CO}_{2}$ increase totalled $30 \%$ to $45 \%$.

The overall effects of the CIE conversion for dual-fuel operation on the energy efficiency and emissions are provided in Table 8.

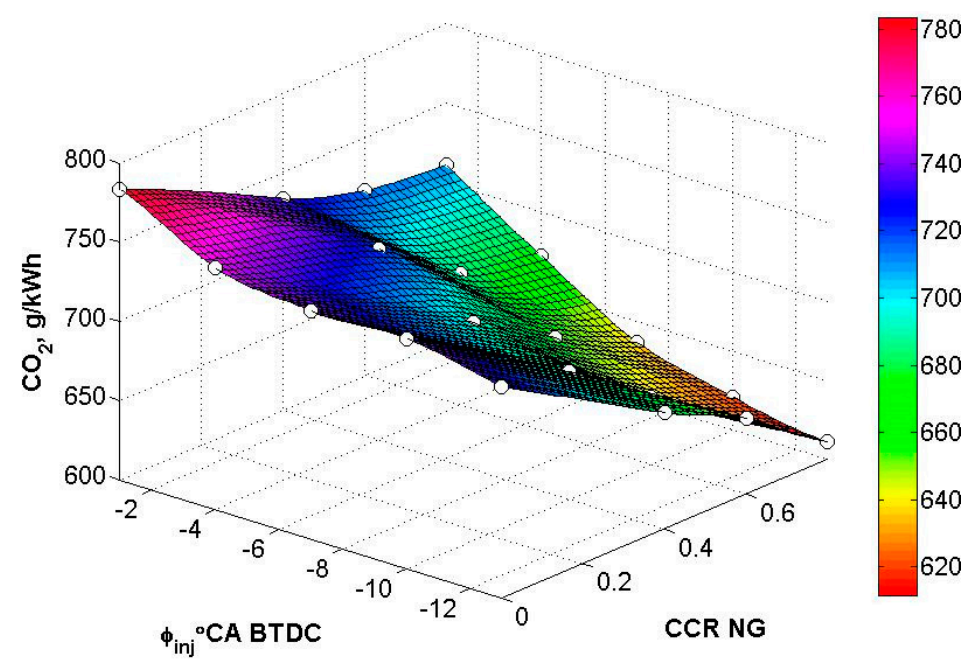

(a)

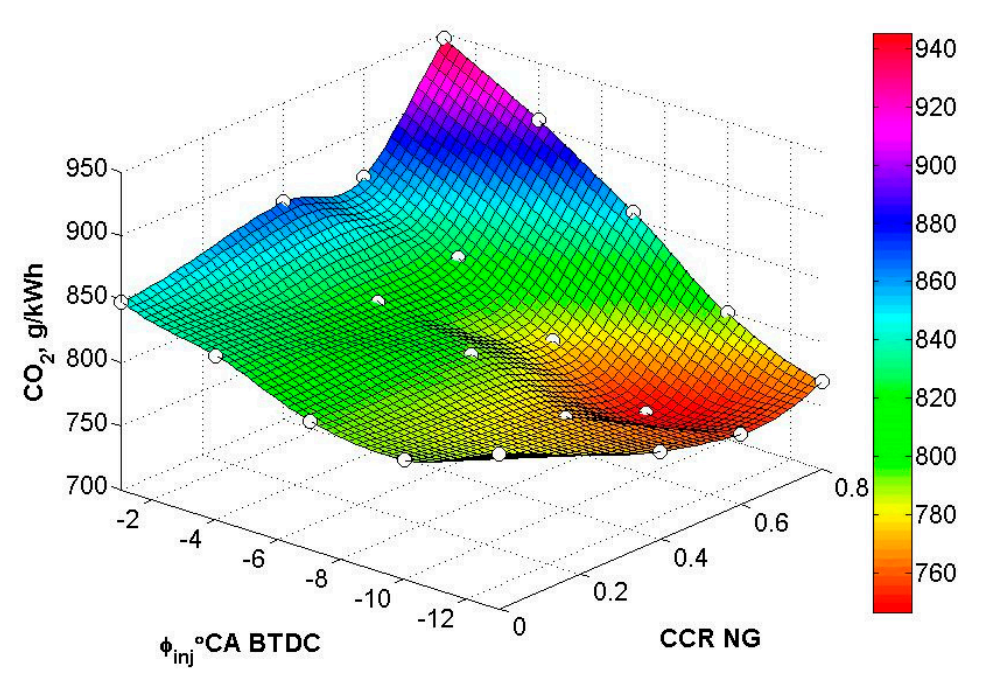

(b)

Figure 9. Cont. 


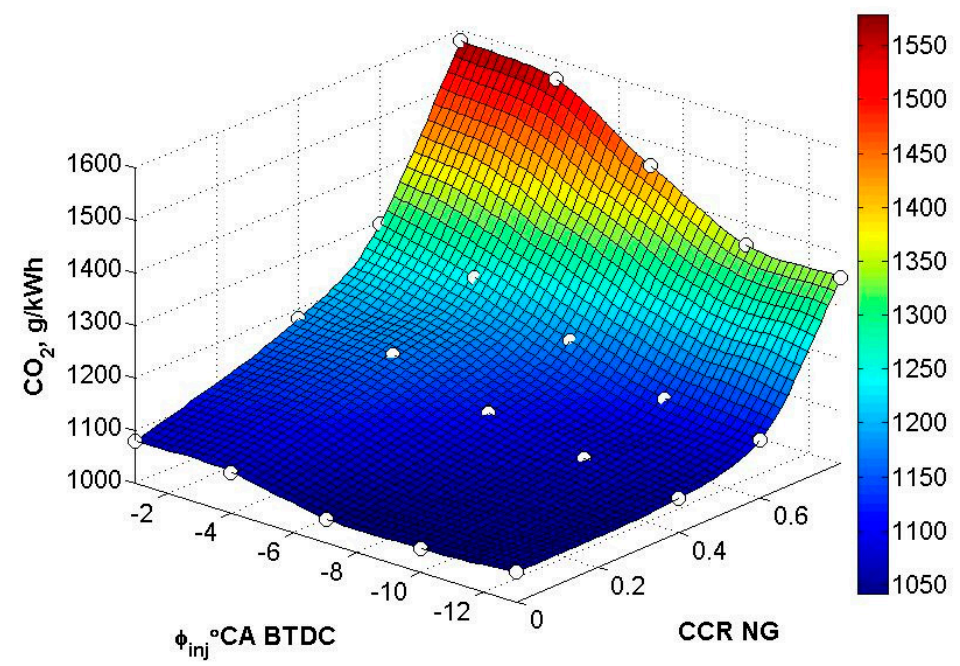

(c)

Figure 9. Influence of dual-fuel CCR NG portion and $\varphi_{\text {inj }}$ on $\mathrm{CO}_{2}$ emissions $\left(n=2000 \mathrm{~min}^{-1}\right)$ : (a) HLM; (b) MLM; (c) LLM. The dots in the graph represent the experimental data.

Table 8. Influence of investigated engine (79.5/95.5) conversion to operation with NG fuel feed on energy efficiency and emission parameters.

\begin{tabular}{|c|c|c|c|c|c|c|c|c|}
\hline \multicolumn{9}{|c|}{ Operating mode: HLM $P_{m e}=5.98$ bar } \\
\hline \multicolumn{9}{|c|}{ Changes in engine parameters when $C C R$ NG increases from 0 to 0.2} \\
\hline $\begin{array}{l}\text { Stationary } \\
\varphi_{\text {inj }},{ }^{\circ} \mathrm{CA}\end{array}$ & $\begin{array}{c}\text { Advanced to } \\
\varphi_{\text {inj }},{ }^{\circ} \mathrm{CA}\end{array}$ & $\Delta \eta_{e}$ & $\begin{array}{l}\Delta P_{z} \\
\text { bar }\end{array}$ & $\begin{array}{l}\Delta \mathrm{NO}_{\mathrm{x}} \\
\mathrm{g} / \mathrm{kWh}\end{array}$ & $\begin{array}{c}\Delta \mathrm{CO}, \\
\mathrm{g} / \mathrm{kWh}\end{array}$ & $\begin{array}{c}\Delta \mathrm{HC} \\
\mathrm{g} / \mathrm{kWh}\end{array}$ & $\begin{array}{c}\Delta \mathrm{CO}_{2} \\
\%\end{array}$ & $\begin{array}{l}\Delta \mathrm{CO}_{2} \\
\mathrm{~g} / \mathrm{kWh}\end{array}$ \\
\hline-1 & -4 & 0 & +10 & -0.2 & +4 & +0.22 & -9 & -47 \\
\hline-1 & -1 & $-3 \%$ & +5 & -1.2 & +5 & +0.25 & -5.5 & -25 \\
\hline-4 & -7 & $\sim 0.7 \%$ & +7 & +0.2 & +3 & +0.21 & -9 & -34 \\
\hline-4 & -4 & $-3.5 \%$ & 0 & -1.7 & +4 & +0.22 & -6.5 & -16 \\
\hline \multicolumn{9}{|c|}{ Operating mode: HLM $P_{m e}=5.98$ bar } \\
\hline \multicolumn{9}{|c|}{ Changes in engine parameters when $C C R$ NG increases from 0 to 0.4} \\
\hline $\begin{array}{l}\text { Stationary } \\
\varphi_{\text {inj }},{ }^{\circ} \mathrm{CA}\end{array}$ & $\begin{array}{c}\text { Advanced to } \\
\varphi_{i n j},{ }^{\circ} \mathrm{CA}\end{array}$ & $\Delta \eta_{e}$ & $\begin{array}{l}\Delta P_{z} \\
\text { bar }\end{array}$ & $\begin{array}{l}\Delta \mathrm{NO}_{\mathrm{x}} \\
\mathrm{g} / \mathrm{kWh}\end{array}$ & $\begin{array}{c}\Delta \mathrm{CO}, \\
\mathrm{g} / \mathrm{kWh}\end{array}$ & $\begin{array}{c}\Delta \mathrm{HC}, \\
\mathrm{g} / \mathrm{kWh}\end{array}$ & $\begin{array}{c}\Delta \mathrm{CO}_{2} \\
\%\end{array}$ & $\begin{array}{l}\Delta \mathrm{CO}_{2} \\
\mathrm{~g} / \mathrm{kWh}\end{array}$ \\
\hline-1 & -4 & $-2.9 \%$ & +9 & -0.9 & +6 & +0.45 & -15 & -63 \\
\hline-1 & -1 & $-6.5 \%$ & +4 & -1.7 & +10 & +0.5 & -9 & -49 \\
\hline-4 & -10 & $-1.3 \%$ & +23 & +2.6 & $+5,5$ & +0.42 & -16 & -72 \\
\hline-4 & -7 & $-3.5 \%$ & +7 & -0.6 & +6 & +0.45 & -15 & -60 \\
\hline-4 & -4 & $-6.4 \%$ & 0 & -1.2 & +8 & +0.45 & -12 & -32 \\
\hline \multicolumn{9}{|c|}{ Operating mode: MLM $P_{m e}=3.98$ bar } \\
\hline \multicolumn{9}{|c|}{ Changes in engine parameters when $C C R$ NG increases from 0 to 0.4} \\
\hline $\begin{array}{l}\text { Stationary } \\
\varphi_{\text {inj }},{ }^{\circ} \mathrm{CA}\end{array}$ & $\begin{array}{l}\text { Advanced } \\
\text { to } \varphi_{i n j},{ }^{\circ} \mathrm{CA}\end{array}$ & $\Delta \eta_{e}$ & $\begin{array}{l}\Delta P_{z} \\
\text { bar }\end{array}$ & $\begin{array}{l}\Delta \mathrm{NO}_{\mathrm{x}} \\
\mathrm{g} / \mathrm{kWh}\end{array}$ & $\begin{array}{c}\Delta \mathrm{CO}, \\
\mathrm{g} / \mathrm{kWh}\end{array}$ & $\begin{array}{c}\Delta \mathrm{HC}, \\
\mathrm{g} / \mathrm{kWh}\end{array}$ & $\begin{array}{c}\Delta \mathrm{CO}_{2} \\
\%\end{array}$ & $\begin{array}{l}\Delta \mathrm{CO}_{2} \\
\mathrm{~g} / \mathrm{kWh}\end{array}$ \\
\hline-1 & -7 & $+1.5 \%$ & +24 & +1.1 & +9.0 & +0.36 & -6.2 & -50 \\
\hline-1 & -4 & $\sim 0 \%$ & +9 & -0.7 & +9.7 & +0.43 & -3.9 & -32 \\
\hline-1 & -1 & $-6.5 \%$ & +1 & -1.7 & +10 & +0.50 & 2.7 & +24 \\
\hline-4 & -10 & 0 & +13 & +2.1 & +7.0 & +0.30 & -7.3 & -56 \\
\hline-4 & -7 & $-1.5 \%$ & +10 & -1.1 & +9.0 & +0.35 & -3.8 & -30 \\
\hline-4 & -4 & $-4 \%$ & 0 & -3.0 & +9.9 & +0.43 & -1.5 & -12 \\
\hline
\end{tabular}


The evaluation encompassed different $\eta_{e}$ compensation possibilities, from $\varphi_{i n j}$ advancement from full $\eta_{e}$ establishment when the engine was operating on diesel to $\varphi_{i n j}=i d e m$.

When diesel is exchanged for NG (CCR NG 0.2), it is more rational to use partial $\varphi_{i n j}$ advancement (with the purpose of re-establishing a proper $\eta_{e}$ ). In the $P_{m e}=1.99$ bar mode, where a decrease in $\eta_{e}$ of $3 \%$ to $3.5 \%$ was observed, the increase in $P_{\max }$ did not exceed 5 bar. A significant decrease in $\mathrm{NO}_{\mathrm{x}}$ was achieved at $1.2 \mathrm{~g} / \mathrm{kWh}$, the $\mathrm{HC}$ increase did not exceed $0.2 \mathrm{~g} / \mathrm{kWh}$, and the $\mathrm{CO}_{2}$ emissions decreased. For the MLM with $P_{m e}=3.98 \mathrm{bar}$, the $\eta_{e}$ deterioration also did not exceed $3 \%$ to $3.5 \%, P_{\max }$ increased by 7 to 9 bar, and $\mathrm{CO}_{2}$ decreased by $15 \%$.

A CCR NG portion increase to 0.4 it is more appropriate for use in partial $\varphi_{i n j}$ advancement. The engine parameter changes are not significantly different from those of the CCR NG 0.2 values. An effect of a decrease of approximately $15 \%$ in $\mathrm{CO}_{2}$ emissions detected compared to operation on diesel only.

However, the $\mathrm{HC}$ emissions increase is not critical, because a valid standard regulates the total $\mathrm{NO}_{x}+\mathrm{HC}$ emissions [52]. The sum of the $\mathrm{NO}_{\mathrm{x}}$ and $\mathrm{HC}$ emissions in the investigated engine conversion to NG was decreased, because the decrease in the absolute $\mathrm{NO}_{\mathrm{x}}$ exceeded the increase in $\mathrm{HC}$ emissions (see Table 8). As a result, the only increase was in the CO emissions. Very few road transport engine $\mathrm{CO}$ emissions are regulated by secondary harmful emission control technologies (oxidation-type neutralisations) $[45-47,51,52]$. Moreover, marine-purpose power plant $\mathrm{CO}$ emissions are not regulated. However, DE conversion for dual-fuel operation purposes exhibits complex improvements in energy efficiency and emission values for conducting research and identifying rational solutions.

\subsection{Engine Parameter Improvement Field Evaluation}

With reference to previously conducted research on HRF, an injection timing advancement in the range of -1 to $-13^{\circ} \mathrm{CA}$ BTDC to improve converted CIE operation into dual-fuel is not very effective, because it is strongly related to an intensive increase in $P_{\max }$ and $\mathrm{NO}_{\mathrm{x}}$.

The search for rational engine parameters has mainly focused on improving the energy efficiency-particularly the operation indicated process efficiency $\eta_{i}$. Based on internal combustion engine classical theory rules $[39,40,52,53]$, changes in $\eta_{i}$ during experiments and improvement reserves are analysed in coordination with heat release dynamics in the engine cylinder, as well as the main operation process parameters (air excess ratio $\alpha$, dynamic parameters such as $P_{\max }$, and auto-ignition delay period $\varphi_{i}$, among others).

As established in Section 3.2, the increase in the CCR NG under $\varphi_{i n j}=i d e m$ conditions influences the combustion process movement towards expansion stroke, and increases the combustion process period-one of the main $\eta_{i}$ influencing factors (see Figure 10). The graph in Figure 10 contains integral heat release characteristic data in the relative form of $X=f(\varphi)$, and indicates a partially meaningful decrease about $X$ during the expansion stroke, which is even more evident when there a larger portion of CCR NG and lower engine load exist.

Larger changes in $X=f(\varphi)$ are characteristic for low dynamic engine cycles $\left(\varphi_{i n j}=\right.$ 1 to $4{ }^{\circ} \mathrm{CA}$ BTDC). For an earlier $\varphi_{i n j}$, the differences among the $X=f(\varphi)$ characteristics decrease.

For change evaluation of the quantitative heat release characteristics, the relationship with the $\eta_{i}$ uses $50 \%$ of the released heat phase $\mathrm{CA}_{50}$ in practice is commonly applied to engine cycle process energy efficiency evaluation $[30,33]$. A direct relationship exists between the $C C R N G$ and $C_{50}$ parameter interaction: in the HLM, when $\mathrm{CA}_{50}$ increased from 0 to 0.8 , an increase of $4^{\circ} \mathrm{CA}$ occurred; in the MLM, an increase of $12{ }^{\circ} \mathrm{CA}$ occurred; and in the LLM, an increase of $42{ }^{\circ} \mathrm{CA}$ occurred. When increasing the engine cycle dynamics ( $\varphi_{i n j}=13^{\circ} \mathrm{CA}$ BTDC), the $\mathrm{CA}_{50}$ exchange of $C C R N G$ in equal parts decreased intensely; for example, up to $6{ }^{\circ} \mathrm{CA}$ and $14^{\circ} \mathrm{CA}$ for the MLM and LLM, respectively. 


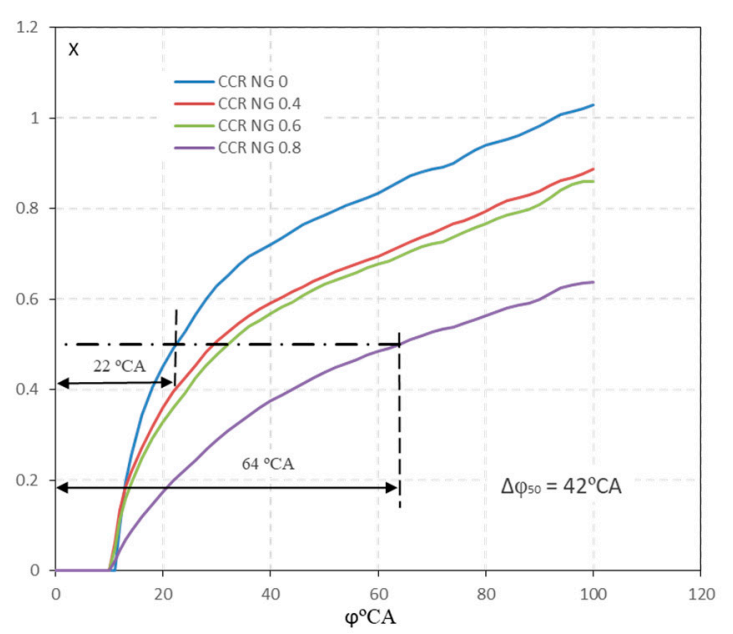

(a)

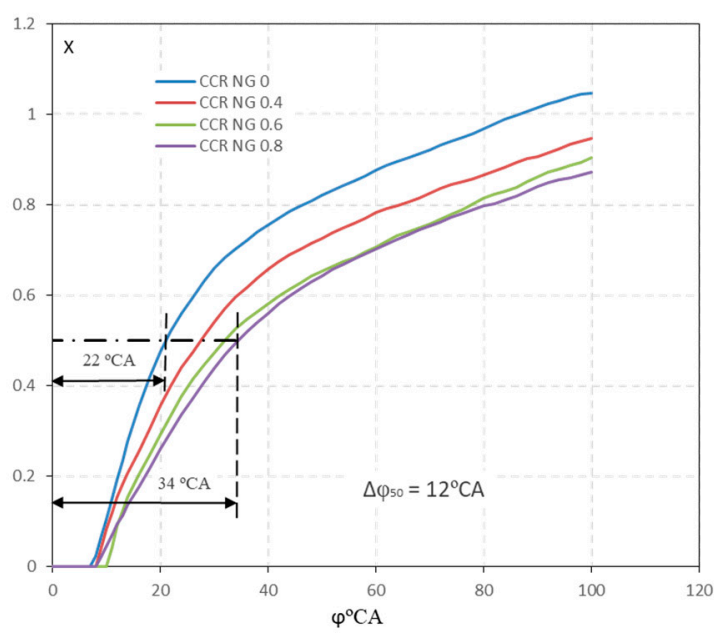

(b)

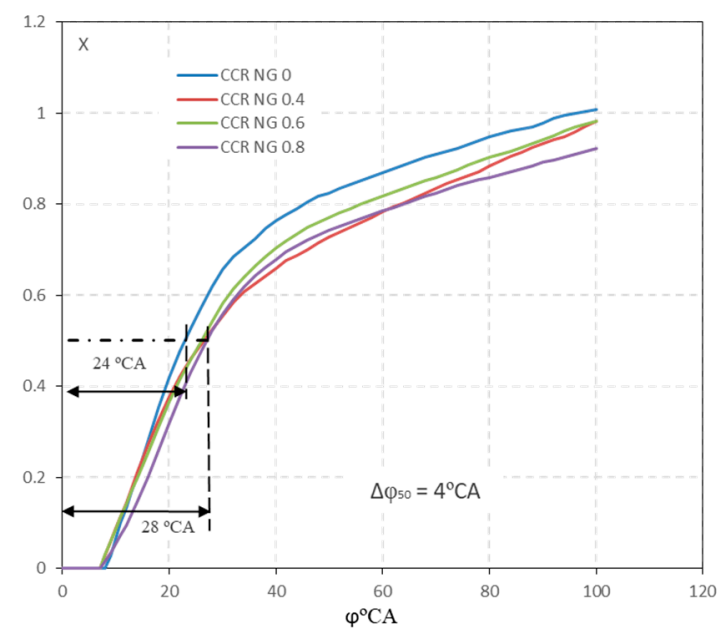

(c)

Figure 10. Dual-fuel engine CCR NG fuel portion influence on heat release characteristics: (a) HLM; (b) MLM; (c) LLM.

Based on the postulate that the ignition delay has a significant influence $\left(\varphi_{z}\right.$, based on evaluation of the I.I. Vibe heat release model) on $\eta_{i}$ [54-56], it is appropriate to analyse the relationship between $\varphi_{z}$ and the engine cycle parameters. For this purpose, Woschi's mathematical modelling I.I. Vibe combustion period $\varphi_{z}$ analytical dependency on the engine cycle implementation parameters was used [57,58]:

$$
\varphi_{z}=\varphi_{z_{0}}\left(\frac{n}{n_{0}}\right)^{m}\left(\frac{\alpha_{0}}{\alpha}\right)^{k} .
$$

Here, the " 0 " index is assigned to the respective parameter values, and is also known as the "basis" engine cycle mode, for which it is usual to accept the nominal power mode; $n$ indicates the engine revolutions; $\alpha$ is the excess air ratio; and $m$ and $k$ are engine constants over a wide range of fuel types $[56,57]$. It should be noted that the $\varphi_{z}$ dependency was established based on a large scope of diesel engine experimental data.

In accordance with the $\varphi_{z}$ expression during $n=i d e m$, the variable $(\alpha)$ remains the main influencing factor on the $\varphi_{z}$ period, as well as when evaluating the relationship between $\eta_{i}$ and $\varphi_{z}$, and the energy efficiency in the engine cycle parameter $\eta_{i}[58,59]$. A change in the CCR NG fuel portion in different load modes attests to the following (see Figure 11): 
- An increase in the amount of $C C R$ NG has an inverse effect on the $\alpha$ value, which can be explained by a partial exchange of air with NG, as well as NG having a larger stoichiometric coefficient compared to diesel-17 kg air $/ \mathrm{kg}$ NG versus $14.6 \mathrm{~kg}$ air $/ \mathrm{kg}$ diesel when the engine is operating in different modes (when the engine is operating in different modes, the CCR NG/air inlet pressure $P_{k}$ remains constant).

- The largest effect from the CCR NG fuel portion on $\alpha$ was detected in the LLM, and decreased significantly when $\varphi_{i n j}$ was advanced.

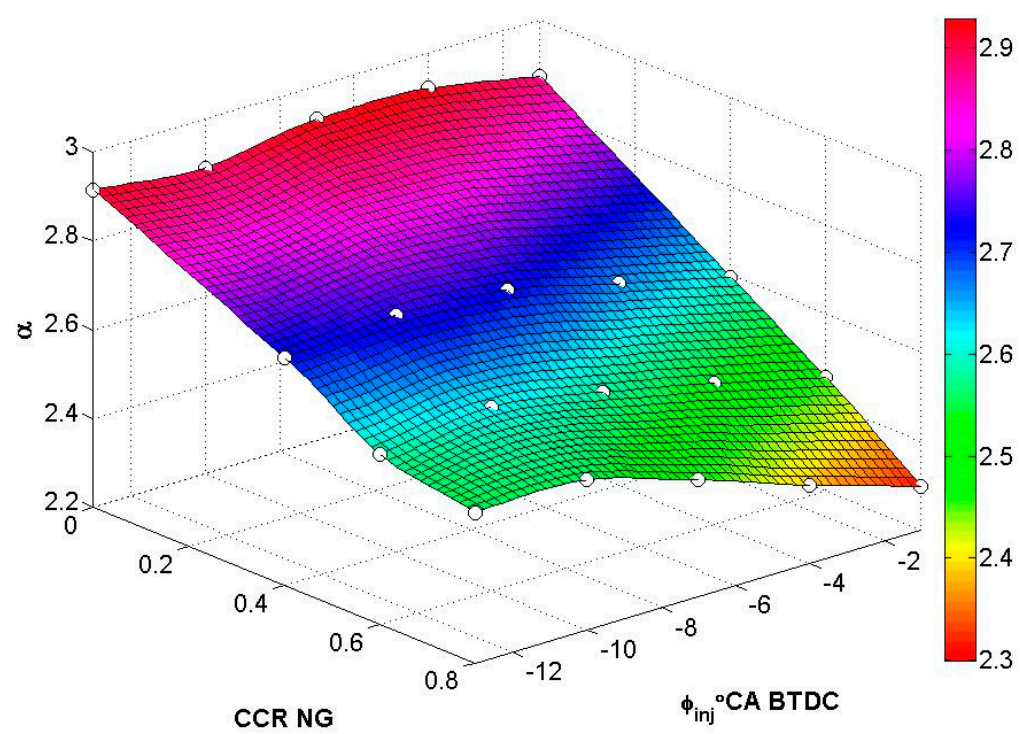

(a)

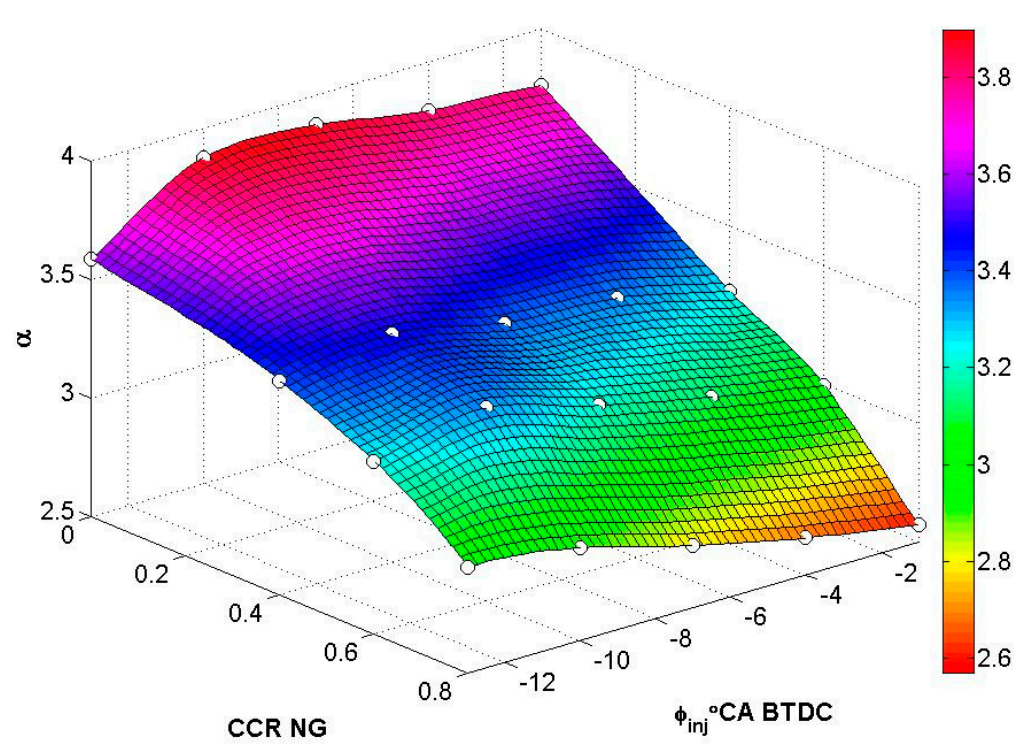

(b)

Figure 11. Cont. 


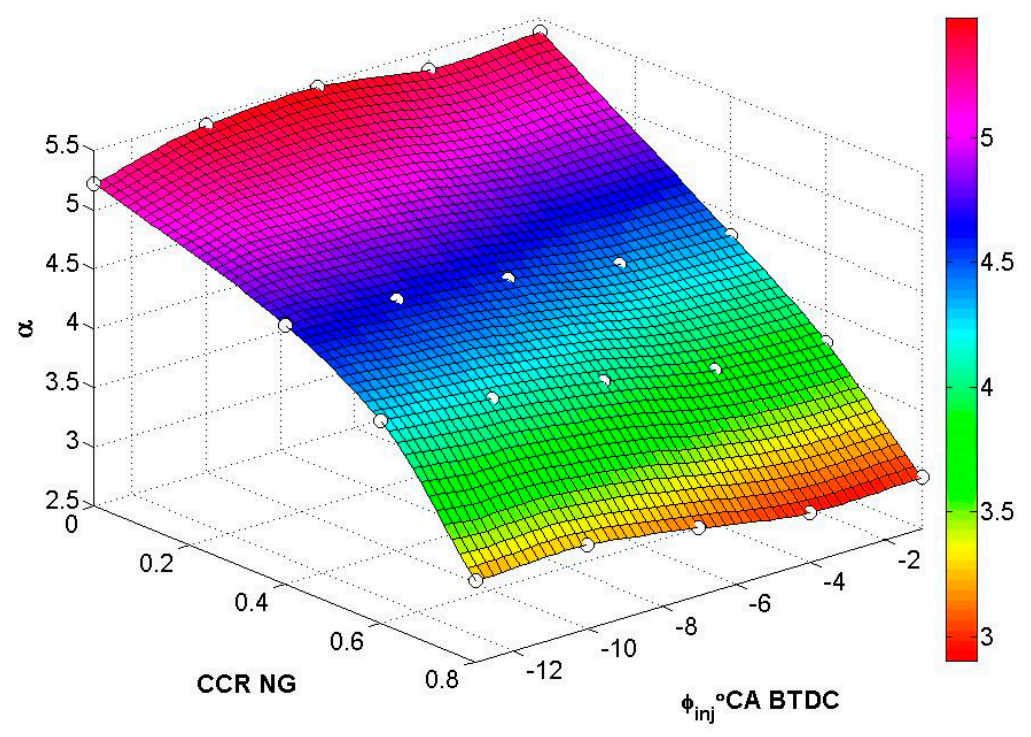

(c)

Figure 11. Influence of dual-fuel CCR NG portion and $\varphi_{\text {inj }}$ on $\alpha(n=2000 \mathrm{rpm})$ : (a) HLM; (b) MLM; (c) LLM. The dots in the graph represent the experimental data.

The changes in the parameter $(\alpha)$ are attuned with the changes in the parameter $\left(\eta_{i}\right)$ arising from the same factors of $C C R N G$ and $\varphi_{\text {inj }}$ (see Figure 12 compared to Figure 11).

On this basis, the composed graphical $\eta_{i}$ and $\alpha$ dependencies (see Figure 13a) confirm that $\alpha$ has a meaningful influence on the engine cycle $\eta_{i}$. The investigated engine load modes of $P_{m e}-$ idem exhibited similar dependencies of $\eta_{i}=f(\alpha)$, independent of the CCR NG and $\varphi_{i n j}$ values. The determinant coefficient $R^{2}=0.8$ to 0.994 attests to the strong correlations of the $\eta_{i}$ and $\alpha$ parameters.

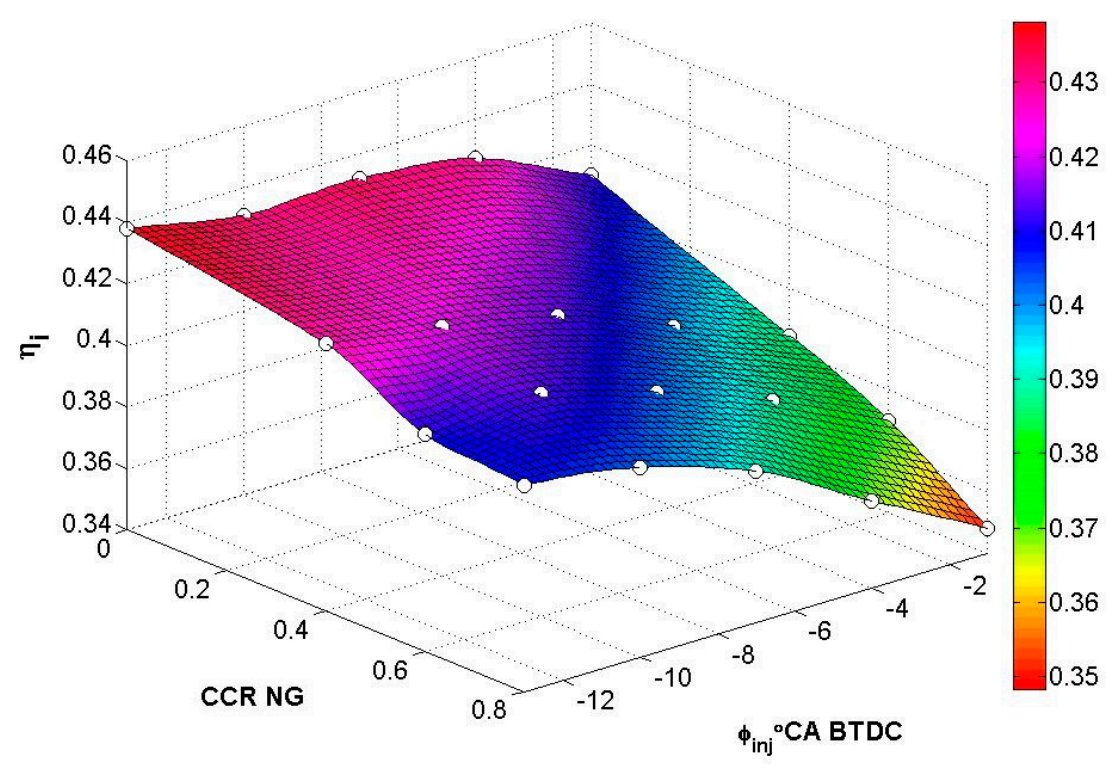

(a)

Figure 12. Cont. 


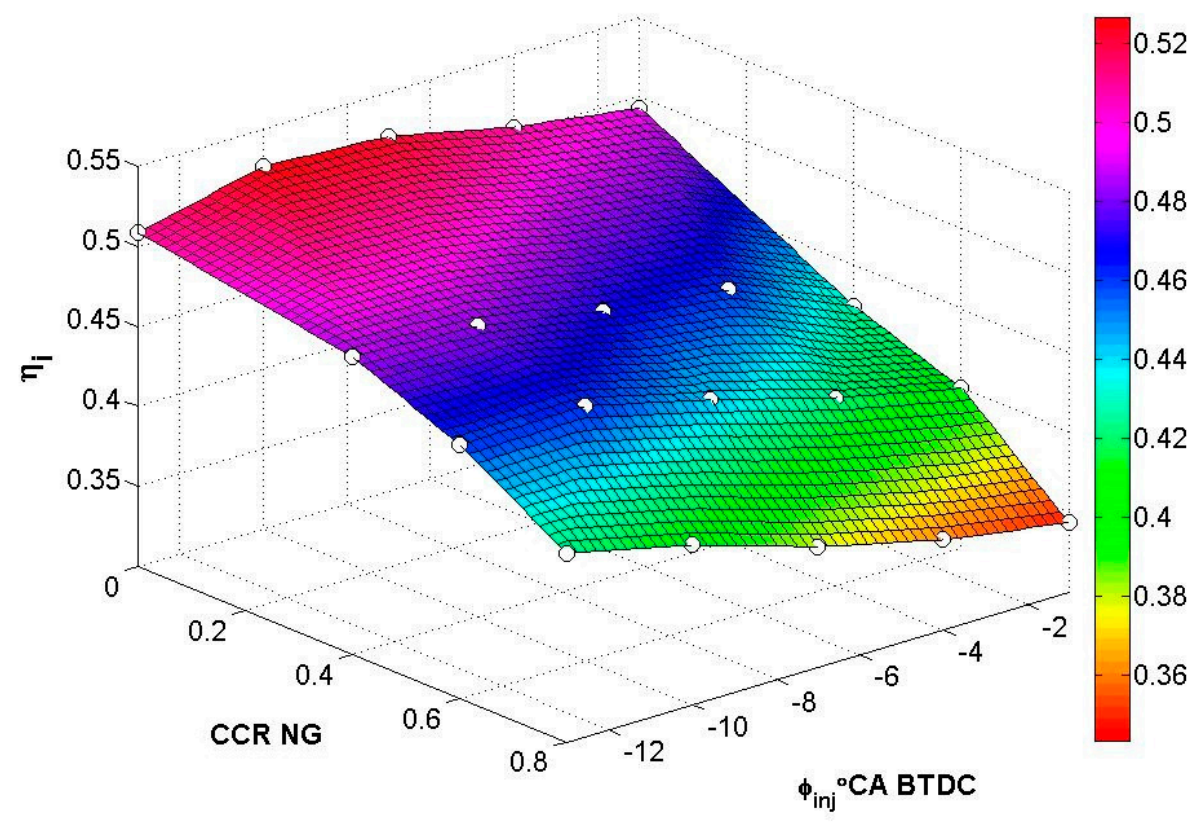

(b)

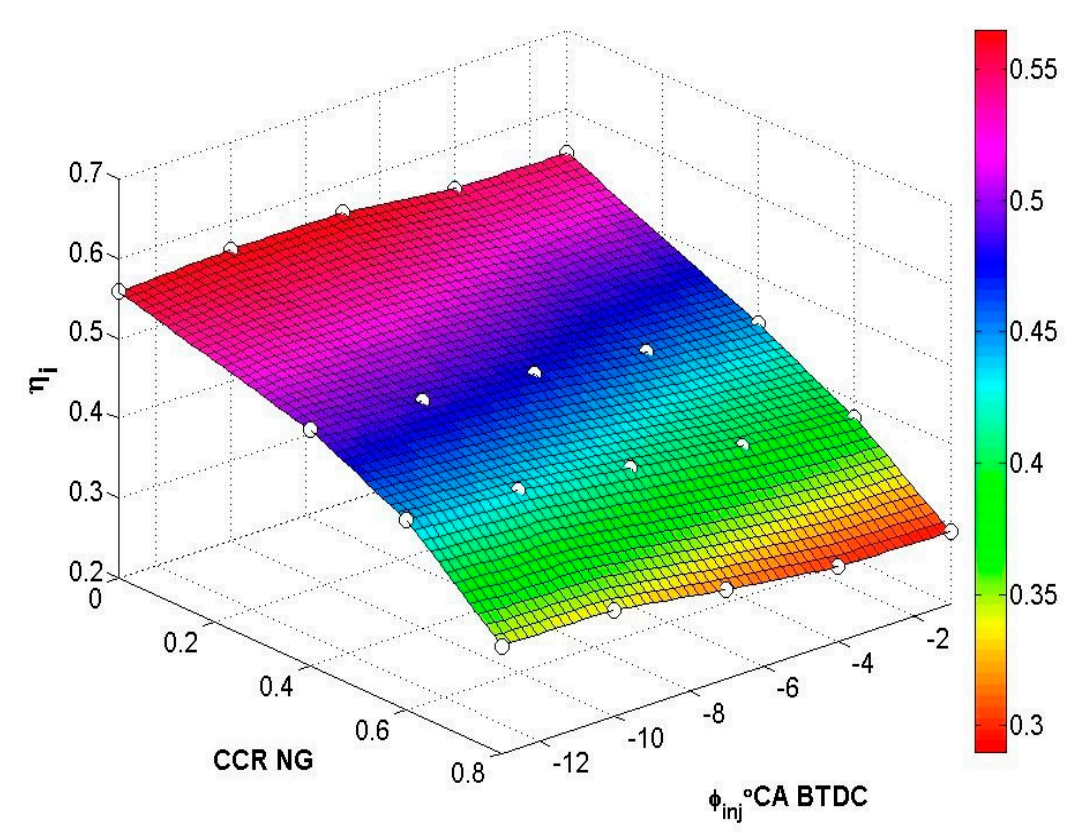

(c)

Figure 12. Influence of dual-fuel CCR NG portion and $\varphi_{\text {inj }}$ on $\alpha\left(n=2000 \mathrm{~min}^{-1}\right):$ (a) HLM; (b) MLM; (c) LLM. The dots in the graph represent the experimental data.

The ratio change of the dependency of parameters $\bar{\eta}_{i}$ and $\alpha$ comes close to a functional with $R^{2} \approx 1.0$ (see Figure $13 \mathrm{~b}$ ).

In a practical sense, the increase in the parameter $(\alpha)$ for a converted DE does not result in many technological difficulties. The increase in the supply of air to the ICE engine cycle can be ensured by changing the air compression equipment to that with a higher capacity or modifying the current compressor [52]. 


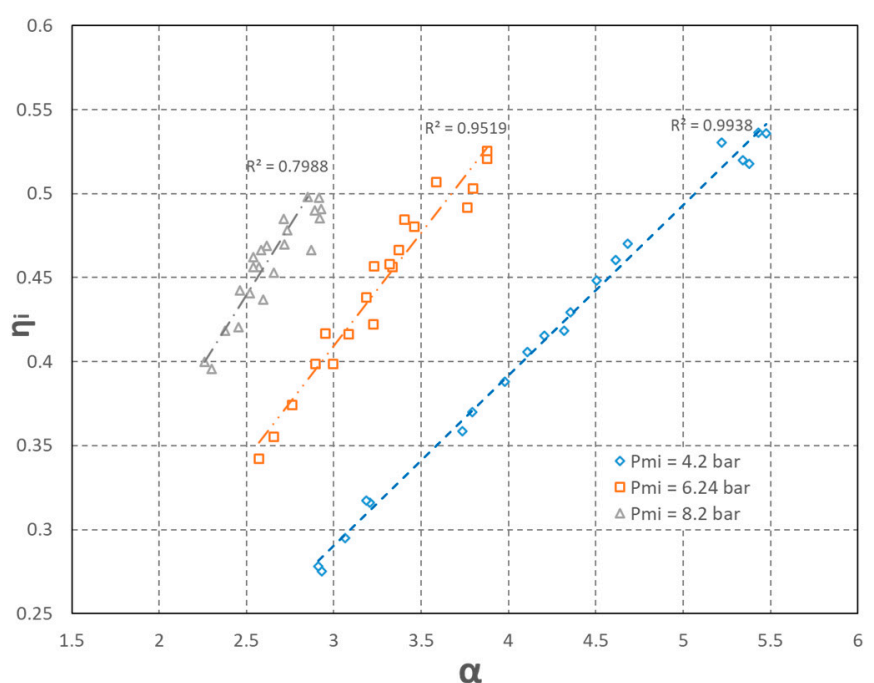

(a)

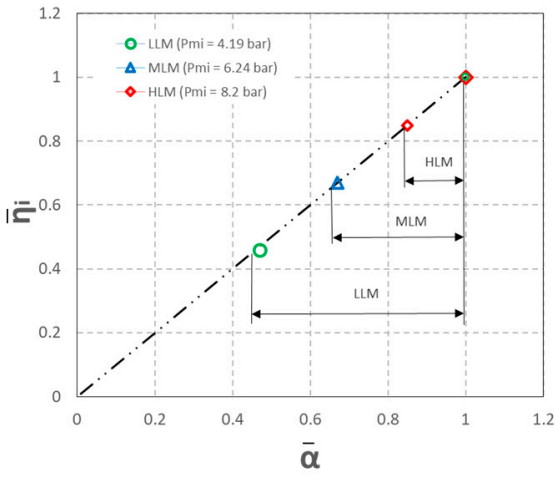

(b)

Figure 13. (a) Relationship between $\eta_{i}$ and $\alpha$ during dual-fuel engine operation with different loads of CCR NG and $\varphi_{i n j}\left(C C R N G=0\right.$ to 0,$8 ; \varphi_{i n j}=1$ to $13^{\circ} \mathrm{CA}$ BTDC). (b) Relationship between $\overline{\eta_{i}}$ and $\bar{\alpha}$ with dual-fuel engine operating on different loads of CCR NG and $\varphi_{\text {inj }}$.

The established relationship between $\eta_{i}$ and $\alpha$ attests to the fact that $\alpha$ is not the only variable that forms the $\eta_{i}$ value. The engine cycle energy efficiency is also determined by other factors, because it is demonstrated that an increase in the engine load, at the same values of $\alpha$, leads to an increase in $\eta_{i}$ (see Figure 13a). Additional factors influencing $\eta_{i}$ may be other engine cycle dynamics parameters: $P_{\max }$ and the change in pressure $\lambda=P_{\max } / P_{c}$ (here, $P_{c}$ is the pressure at TDC) [58]. An increase in the load leads to an increase in the engine cycle dynamic parameters. It also likely that an increase in the fuel macro- and micro-turbulence influences the combustion intensity positively [40,58]. During large load modes, an increase in the air inlet pressure and the respective air-NG mixture movement speed through the air inlet valve accelerates the fuel combustion main diffusion phase, resulting in an increase in $\eta_{i}$ [59].

Micro- and macro-turbulence accelerate the active radical $\mathrm{OH}$ and local combustion centre diffusion into the cylinder periphery, ensuring an entire volume combustion process $[40,60]$.

An analogous energy efficiency increase result was obtained in the works of $[28,33]$, where a non-traditional CIE cycle HRF injection timing angle advancement of up to $50^{\circ} \mathrm{CA}$ BTDC was used. As noted previously, the energy efficiency increase of a converted CIE for dual-fuel operation also manifests itself as a method for emission control when operating on NG. An increase in the air mass during the engine cycle leads to a decrease in the PM, CO, and HC emissions [19,61-63]. As well as the temperature field being equalised in the cylinder during combustion, there is also a decrease in the number of combustion centre concentrations in the cylinder, and as a result, a decrease in the $\mathrm{NO}_{\mathrm{x}}$ emissions $[27,33,63]$. An important improvement effect on $\eta_{i}$ is the greenhouse gas $\mathrm{CO}_{2}$ emission decrease, as observed in the LLM and MLM, owing to the smaller portion of carbon in the chemical composition of NG of 0.75 compared to diesel with 0.86 .

\section{Conclusions}

The energy efficiency and emissions of a converted (Bore $79.5 \mathrm{~mm} /$ Stroke $95 \mathrm{~mm}$ ) CIE for operation on dual D and NG fuel were established through experimental research:

- A deterioration in the energy efficiency was established when increasing the NG portion in the energy balance up to $80 \%$ or the CCR NG up to 0.8 : in the HLM, 7 to $15 \%$; in the MLM, 15 to $38 \%$, and in the LLM, 40 to $45 \%$. 
- An increase occurred in the incomplete combustion products in exhaust gases: the HC could exceed 30 times in the HLM and MLM and up to 80 times in LLM with $0.1 \mathrm{~g} / \mathrm{kWh}$ while operating on $\mathrm{D}$; the $\mathrm{CO}$ increased up to 30 times from $0.5 \mathrm{~g} / \mathrm{kWh}$; although the emissions of the most harmful pollutant, $\mathrm{NO}_{\mathrm{x}}$, decreased approximately 4 to 5 times.

- The pilot D portion HRF injection timing DIT optimisation with respect to energy efficiency could be practically effective only when it did not exceed a $C C R N G$ of 0.4 when the engine was operating in the HLM $\left(P_{m e} \sim 6\right.$ bar $)$ : by advancing DIT by 3 to $6^{\circ} \mathrm{CA}$, the $\mathrm{NO}_{\mathrm{x}}+\mathrm{HC}$ emissions decreased by 10 to $15 \%$; in the MLM and LLM, DIT optimisation did not have a positive effect.

The indicated process parameter analysis in the investigated CCR NG $=0$ to 0,8 and DIT $=-1$ to $-13^{\circ} \mathrm{CA}$ BTDC range attests to the fact that conversion of a CIE for NG operation does not undermine the CIE characteristic interdependent correlated cycle indicated efficiency and characteristic parameters (such as $\alpha$ and $P_{\max }$ ). On this basis, one of the main reasons for the deterioration in $\eta_{i}$ when the engine is converted for NG operation was the NG combustion phase increase in the expansion stroke, and therewith, the associated cylinder air excess deterioration (evaluated by the air excess ratio $\alpha$ ).

The research results can be used for the evaluation of similar experiments, in which converted CIEs with conventional fuel injection systems for operation with dual-fuel feed without significant changes to the engine design were used.

Author Contributions: Conceptualization, S.L. and S.P.; methodology, S.L., V.D. and A.R.; software, M.M and V.D.; formal analysis, V.D.; validation, A.R. and M.M.; writing - original draft preparation, S.L., L.J. and V.D.; writing - review and editing, S.L. and L.J.; supervision, S.L. and S.P.; project administration, S.L.

Funding: This research received no external funding.

Conflicts of Interest: The authors declare no conflicts of interest.

\section{Nomenclature}

$k \quad$ Optical absorption coefficient $\left(\mathrm{m}^{-1}\right)$

$n \quad$ Rotational speed of the crankshaft $\left(\mathrm{min}^{-1}\right)$

$T_{g} \quad$ Exhaust gas temperature (K)

$T_{K} \quad$ Air temperature after compressor $(\mathrm{K})$

$P_{e} \quad$ Brake power $(\mathrm{kW})$

$\alpha \quad$ Excess air coefficient

$\beta \quad$ Fuel excess coefficient

$\varepsilon \quad$ Compression ratio

$\varphi_{i n j}\left(\phi_{i n j}\right) \quad$ High reaction fuel injection time $\left({ }^{\circ} \mathrm{CA}\right)$

$H_{U} \quad$ Lower heating value $(\mathrm{kJ} / \mathrm{kg})$

$\eta_{m} \quad$ Mechanical efficiency coefficient

$\eta_{i} \quad$ Indicated thermal efficiency

$\eta_{e} \quad$ Brake thermal efficiency

$P_{\max } \quad$ Maximal cylindrical pressure (bar)

$P_{k} \quad$ Air pressure after compressor (bar)

$\lambda=\frac{P_{z}}{P_{c}} \quad$ Cylinder pressure increase rate

$X=f(\varphi) \quad$ Relative heat release ratio $\left({ }^{\circ} \mathrm{CA}\right)$

$\frac{d Q}{d \varphi} \quad$ Heat release rate $\left(\mathrm{kJ} /{ }^{\circ} \mathrm{CA}\right)$

$P_{m e} \quad$ Brake mean effective pressure (bar)

$P_{m i} \quad$ Indicated mean effective pressure (bar)

$P_{c y l} \quad$ Pressure in cylinder (bar)

$C A_{50} \quad$ Half of heat released during cycle $\left({ }^{\circ} \mathrm{CA}\right)$

$(d P / d \varphi)_{\text {max }} \quad$ Maximum pressure increase rate in cylinder (bar $\left./{ }^{\circ} \mathrm{CA}\right)$

$(d P / d \varphi)_{\text {mid. }} \quad$ Average pressure increase rate in cylinder (bar/ $\left.{ }^{\circ} \mathrm{CA}\right)$ 


\section{Abbreviations}

$\begin{array}{ll}\text { CIE } & \text { Compression ignition engine } \\ \text { CR } & \text { Common rail fuel injection } \\ \text { CCR NG } & \text { Co-combustion ratio of natural gas } \\ \text { CC } & \text { Combustion chamber } \\ \text { DIT } & \text { Diesel fuel injection timing } \\ \text { HRR } & \text { Heat release rate } \\ \text { HRF } & \text { High reaction fuel } \\ \text { HLM } & \text { High load mode } \\ \text { MLM } & \text { Medium load mode } \\ \text { LLM } & \text { Low load mode } \\ \text { ULLM } & \text { Ultra-low load mode } \\ \text { BTDC } & \text { Before top dead centre } \\ \text { ATDC } & \text { After top dead centre } \\ \text { CA } & \text { Crank angle } \\ \text { CNG } & \text { Compressed natural gas } \\ \text { LNG } & \text { Liquefied natural gas } \\ \text { CO } & \text { Carbon monoxide } \\ \text { HC } & \text { Hydrocarbon } \\ \text { NG } & \text { Natural gas } \\ \text { NO } & \text { Nitrous oxide } \\ \text { CO } 2 & \text { Carbon dioxide }\end{array}$

\section{References}

1. Chen, Z.; Yao, C.; Wang, Q.; Han, G.; Dou, Z.; Wei, H.; Wang, B.; Liu, M.; Wu, T. Study of Cylinder-to-Cylinder Variation in a Diesel Engine Fueled with Diesel/Methanol Dual Fuel. Fuel 2016, 170, 67-76. [CrossRef]

2. Greenhouse Gas Emissions from Transport. Available online: https://www.eea.europa.eu/data-and-maps/ indicators/transport-emissions-of-greenhouse-gases/transport-emissions-of-greenhouse-gases-11 (accessed on 30 May 2019).

3. Kumar, S.; Cho, J.; Park, J.; Moon, I. Advances in Diesel-Alcohol Blends and Their Effects on The Performance and Emissions of Diesel Engines. Renew. Sustain. Energy Rev. 2013, 22, 46-72. [CrossRef]

4. Cheenkachorn, K.; Poompipatpong, C.; Ho, C. Performance and Emissions of a Heavy-Duty Diesel Engine Fuelled With Diesel and LNG (Liquid Natural Gas). Energy 2013, 53, 52-57. [CrossRef]

5. Frei, J.K.; Orenic, C.; Smith, N. Effects of Acid Rain on Epiphytic Orchid Growth. Stud. Environ. Sci. 1984, 25, 271-285. [CrossRef]

6. Pedrozo, V.; May, I.; Dalla Nora, M.; Cairns, A.; Zhao, H. Experimental Analysis of Ethanol Dual-Fuel Combustion in a Heavy-Duty Diesel Engine: An Optimisation at Low Load. Appl. Energy 2016, 165, 166-182. [CrossRef]

7. Nithyanandan, K.; Lin, Y.; Donahue, R.; Meng, X.; Zhang, J.; Lee, C. Characterization of Soot From Diesel-CNG Dual-Fuel Combustion In A CI Engine. Fuel 2016, 184, 145-152. [CrossRef]

8. Liu, J.; Zhang, X.; Wang, T.; Zhang, J.; Wang, H. Experimental and Numerical Study of The Pollution Formation in a Diesel/CNG Dual Fuel Engine. Fuel 2015, 159, 418-429. [CrossRef]

9. Arteconi, A.; Brandoni, C.; Evangelista, D.; Polonara, F. Life-Cycle Greenhouse Gas Analysis of LNG As A Heavy Vehicle Fuel in Europe. Appl. Energy 2010, 87, 2005-2013. [CrossRef]

10. Banapurmath, N.; Budzianowski, W.; Basavarajappa, Y.; Hosmath, R.; Yaliwal, V.; Tewari, P. Effects of Compression Ratio, Swirl Augmentation Techniques and Ethanol Addition on the Combustion Of CNG-Biodiesel In A Dual-Fuel Engine. Int. J. Sustain. Eng. 2013, 7, 55-70. [CrossRef]

11. Abagnale, C.; Cameretti, M.; De Simio, L.; Gambino, M.; Iannaccone, S.; Tuccillo, R. Numerical Simulation and Experimental Test of Dual Fuel Operated Diesel Engines. Appl. Therm. Eng. 2014, 65, 403-417. [CrossRef]

12. Athenstaedt, G. Entwiklung Stationarer Gasmotoren Seit Dem Inkrafttreten Der TA-Luft; Springer: Wiesbaden, Germany, 1993; p. 4.

13. Van Basshuysen, R.; Schäfer, F. Handbuch Verbrennungsmotor; Springer: Berlin, Germany, 2007; p. 1032. 
14. Dietrich, W. Die Gemischbildung Bei Gas-Und Dieselmotoren Sowie Ihr Einfluss Auf Die Schadstoffemissionen-Rückblick Und Ausblick Teil 1. Mtz-Mot. Z. 1999, 60, 28-38. [CrossRef]

15. Woschni, G. Verbrennungsmotoren; TU Munchen: Munchen, Germany, 1988; p. 303.

16. Boretti, A. Numerical Study of The Substitutional Diesel Fuel Energy in a Dual Fuel Diesel-LPG Engine with Two Direct Injectors Per Cylinder. Fuel Process. Technol. 2017, 161, 41-51. [CrossRef]

17. Wang, B.; Li, T.; Ge, L.; Ogawa, H. Optimization of Combustion Chamber Geometry for Natural Gas Engines with Diesel Micro-Pilot-Induced Ignition. Energy Convers. Manag. 2016, 122, 552-563. [CrossRef]

18. Nithyanandan, K.; Zhang, J.; Li, Y.; Meng, X.; Donahue, R.; Lee, C.; Dou, H. Diesel-Like Efficiency Using Compressed Natural Gas/Diesel Dual-Fuel Combustion. J. Energy Resour. Technol. 2016, 138, 052201. [CrossRef]

19. Carlucci, A.; Laforgia, D.; Saracino, R. Combustion Development and Exhaust Emissions of a Dual-Fuel DI Diesel Engine With Variable in-Cylinder Bulk Flow and Methane Supply Strategies. In Proceedings of the ASME 2009 Internal Combustion Engine Division Fall Technical Conference, Lucerne, Switzerland, 27-30 September 2009.

20. Carlucci, A.; Laforgia, D.; Saracino, R. Effects of In-Cylinder Bulk Flow and Methane Supply Strategies on Charge Stratification, Combustion and Emissions of a Dual-Fuel DI Diesel Engine; SAE Technical Paper Series; SAE International: Detroit, MI, USA, 2009. [CrossRef]

21. Mustafi, N.; Raine, R.; Verhelst, S. Combustion and Emissions Characteristics of a Dual Fuel Engine Operated on Alternative Gaseous Fuels. Fuel 2013, 109, 669-678. [CrossRef]

22. Banapurmath, N.; Tewari, P.; Yaliwal, V.; Kambalimath, S.; Basavarajappa, Y. Combustion Characteristics of A 4-Stroke CI Engine Operated on Honge Oil, Neem and Rice Bran Oils When Directly Injected and Dual Fuelled with Producer Gas Induction. Renew. Energy 2009, 34, 1877-1884. [CrossRef]

23. Ramadhas, A.; Jayaraj, S.; Muraleedharan, C. Dual Fuel Mode Operation in Diesel Engines Using Renewable Fuels: Rubber Seed Oil and Coir-Pith Producer Gas. Renew. Energy 2008, 33, 2077-2083. [CrossRef]

24. García Valladolid, P.; Tunestål, P.; Monsalve-Serrano, J.; García, A.; Hyvönen, J. Impact of Diesel Pilot Distribution on The Ignition Process of a Dual Fuel Medium Speed Marine Engine. Energy Convers. Manag. 2017, 149, 192-205. [CrossRef]

25. Carlucci, A.; Ficarella, A.; Laforgia, D.; Strafella, L. Improvement of Dual-Fuel Biodiesel-Producer Gas Engine Performance Acting on Biodiesel Injection Parameters and Strategy. Fuel 2017, 209, 754-768. [CrossRef]

26. Zhang, C.; Song, J. Experimental Study of Co-Combustion Ratio on Fuel Consumption and Emissions of NG-Diesel Dual-Fuel Heavy-Duty Engine Equipped with a Common Rail Injection System. J. Energy Inst. 2016, 89, 578-585. [CrossRef]

27. Papagiannakis, R.; Rakopoulos, C.; Hountalas, D.; Rakopoulos, D. Emission Characteristics of High Speed, Dual Fuel, Compression Ignition Engine Operating in a Wide Range of Natural Gas/Diesel Fuel Proportions. Fuel 2010, 89, 1397-1406. [CrossRef]

28. Carlucci, A.; Ficarella, A.; Laforgia, D. Potentialities of A Common Rail Injection System for The Control of Dual Fuel Biodiesel-Producer Gas Combustion and Emissions. J. Energy Eng. 2014, 140, A4014011. [CrossRef]

29. Carlucci, A.; Colangelo, G.; Ficarella, A.; Laforgia, D.; Strafella, L. Improvements in Dual-Fuel Biodiesel-Producer Gas Combustion at Low Loads Through Pilot Injection Splitting. J. Energy Eng. 2015, 141, C4014006. [CrossRef]

30. Singh, R.; Singh, S.; Pathak, B. Investigations on Operation of CI Engine Using Producer Gas and Rice Bran Oil in Mixed Fuel Mode. Renew. Energy 2007, 32, 1565-1580. [CrossRef]

31. Yousefi, A.; Birouk, M.; Guo, H. An Experimental and Numerical Study of The Effect of Diesel Injection Timing on Natural Gas/Diesel Dual-Fuel Combustion at Low Load. Fuel 2017, 203, 642-657. [CrossRef]

32. Maghbouli, A.; Saray, R.; Shafee, S.; Ghafouri, J. Numerical Study of Combustion and Emission Characteristics of Dual-Fuel Engines Using 3D-CFD Models Coupled With Chemical Kinetics. Fuel 2013, 106, 98-105. [CrossRef]

33. Maurya, R.; Mishra, P. Parametric Investigation on Combustion and Emissions Characteristics of a Dual Fuel (Natural Gas Port Injection and Diesel Pilot Injection) Engine Using 0-D SRM and 3D CFD Approach. Fuel 2017, 210, 900-913. [CrossRef]

34. Zhang, C.; Zhou, A.; Shen, Y.; Li, Y.; Shi, Q. Effects of Combustion Duration Characteristic on the Brake Thermal Efficiency and Nox Emission of a Turbocharged Diesel Engine Fueled with Diesel-LNG Dual-Fuel. Appl. Therm. Eng. 2017, 127, 312-318. [CrossRef] 
35. Li, J.; Wu, B.; Mao, G. Research on The Performance and Emission Characteristics of the LNG-Diesel Marine Engine. J. Nat. Gas. Sci. Eng. 2015, 27, 945-954. [CrossRef]

36. Ivanchenko, N. Visokii Nadduv Dizelei; Mashinnastraenie Leningradskaya Oddelenye: Leningrad, Russia, $1983 ;$ p. 198.

37. Lebedevas, S.; Lebedeva, G. Mathematical Model of Combined Parametrical Analysis of in Indicator Process and Thermal Loading on the Diesel Engine Piston. Transport 2004, 19, 108-118. [CrossRef]

38. Mollenhauer, K.; Tschöke, H. Handbook of Diesel Engines; Springer: Berlin, Germany, 2010.

39. Schwarz, C.; Merker, G.; Stiesch, G.; Otto, F. Simulating Combustion; Springer: Berlin, Germany, 2005.

40. Guzzella, L.; Onder, C. Introduction to Modeling and Control. of Internal Combustion Engine Systems; Springer: Berlin, Germany, 2010.

41. Heywood, J. Internal Combustion Engine Fundamentals; McGraw-Hill: New York, NY, USA, 1988.

42. Lieuwen, T.; Yang, V.; Yetter, R. Synthesis Gas Combustion; CRC Press: Boca Raton, FL, USA, 2010; p. 384.

43. Boehman, A.; Corre, O. Combustion of Syngas in Internal Combustion Engines. Combust. Sci. Technol. 2008, 180, 1193-1206. [CrossRef]

44. Wang, T.; Zhang, X.; Zhang, J.; Hou, X. Numerical Analysis of The Influence of The Fuel Injection Timing and Ignition Position in a Direct-Injection Natural Gas Engine. Energy Convers. Manag. 2017, 149, 748-759. [CrossRef]

45. Daisho, Y.; Yaeo, T.; Koseki, T.; Saito, T.; Kihara, R.; Quiros, E. Combustion and Exhaust Emissions in a Direct-Injection Diesel Engine Dual-Fueled with Natural Gas; SAE Technical Paper Series; SAE International: Detroit, MI, USA, 1995.

46. Dishy, A.; You, T.; Iwashiro, Y.; Nakayama, S.; Kihara, R.; Saito, T. Controlling Combustion and Exhaust Emissions in A Direct-Injection Diesel Engine Dual-Fueled with Natural Gas; SAE Technical Paper Series; SAE International: Detroit, MI, USA, 1995.

47. Faghani, E.; Kheirkhah, P.; Mabson, C.; McTaggart-Cowan, G.; Kirchen, P.; Rogak, S. Effect of Injection Strategies on Emissions From a Pilot-Ignited Direct-Injection Natural-Gas Engine-Part II: Slightly Premixed Combustion; SAE Technical Paper Series; SAE Internaniotal: Detroit, MI, USA, 2017.

48. Air Pollution. Available online: http://www.imo.org/en/OurWork/Environment/PollutionPrevention/ AirPollution/Pages/Air-Pollution.aspx (accessed on 3 April 2019).

49. GHG Emissions. Available online: http://www.imo.org/en/OurWork/Environment/PollutionPrevention/ AirPollution/Pages/GHG-Emissions.aspx (accessed on 3 April 2019).

50. Abdelghaffar, W. Performance and Emissions of a Diesel Engine Converted to Dual Diesel-CNG Fuelling. Eur. J. Sci. Res. 2011, 56, 279-293.

51. Emission Standards: Europe: Nonroad Engines. Available online: https://dieselnet.com/standards/eu/ nonroad.php\#vessel (accessed on 3 April 2019).

52. Krasovskij, I. Izdatel'stvo: Mashinostroenie (Vse Knigi Izdatel'stva) Mesto Izdanija; Leningrad God: Leningrad, Russia, 1983.

53. Kruggel, O. Untersuchungen Zur Stickoxidminderung an Schnelllaufenden Großdieselmotoren; VEB Verlag Technik: Berlin, Germany, 1989; pp. 29-36.

54. Wiebe, I. Brennverlauf Und Kreisprozesse Vonverbrennungsmotoren; VEB Verlag Technik: Berlin, Germany, 1970.

55. Vibe, I. Novoe O Rabochem Cikle Dvigatelej; Moskva-Sverdlovsk: Moscow, Russia, 1962.

56. Woschni, G. Eine Methode Zur Vorausberechnung Der Änderung Des. Brenverlaufs Mittelschnellaufender Dieselmotoren Bei Geanderten Betriebsbedigungen; Springer: Wiesbaden, Germany, 1973; pp. 106-110.

57. Woschni, G. Die Berechnung Der Wandverluste Und Der Thermischen Belastung Von Dieselmotoren; Springer: Wiesbaden, Germany, 1970.

58. Kavtaradze, R. Teorija Porshnevyh Dvigatelej. Special'nye Glavy: Uchebnik Dlja Vuzov; MGTU of N. E. Bauman: Moscow, Russia, 2008; p. 720.

59. Lebedev, S.; Lebedeva, G.; Matievskij, D.; Reshetov, V. Formirovanie Konstruktivnogo Rjada Porshnej Dlja Tipaža Vysokooborotnyh Forsirovannyh Dizelej; Akademija Transporta RF: Barnaul, Russia, 2003; p. 89.

60. Lebedev, S.; Matievskij, D. Analiz Indikatornogo KPD I Harakteristiki Teplovydelenija Dizelej Tiporazmera CN16,518,5 Pri Ih Forsirovanii Do Pme = 2,0 MPa; Vestnik Altajskogo Tehnicheskogo Universiteta: Barnaul, Russia, 2000; pp. 103-107.

61. Zhang, Q.; Li, M.; Shao, S. Combustion Process and Emissions of A Heavy-Duty Engine Fueled With Directly Injected Natural Gas And Pilot Diesel. Appl. Energy 2015, 157, 217-228. [CrossRef] 
62. Mittal, M.; Donahue, R.; Winnie, P.; Gillette, A. Exhaust Emissions Characteristics of a Multi-Cylinder 18.1-L Diesel Engine Converted to Fueled With Natural Gas and Diesel Pilot. J. Energy Inst. 2015, 88, $275-283$. [CrossRef]

63. Taniguchi, S.; Masubuchi, M.; Kitano, K.; Mogi, K. Feasibility Study of Exhaust Emissions in a Natural Gas Diesel Dual Fuel (DDF) Engine; SAE Technical Paper Series; SAE International: Detroit, MI, USA, 2012. 